\title{
The effect of community complexity on species performance profiles along a thermal gradient
}

\author{
David A.J.S. O'Connor
}

This thesis is submitted to the Faculty of Graduate and Postdoctoral Studies in partial fulfillment of the requirements of the degree of

Master of Science

in

Biology.

(C)2011

David O'Connor 
Library and Archives

Canada

Published Heritage Branch

395 Wellington Street

Ottawa ON K1A ON4

Canada
Bibliothèque et

Archives Canada

Direction du

Patrimoine de l'édition

395 , rue Wellington

Ottawa ON K1A ON4

Canada
Your file Votre référence

ISBN: 978-0-494-83126-7

Our file Notre référence

ISBN: 978-0-494-83126-7

\section{NOTICE:}

The author has granted a nonexclusive license allowing Library and Archives Canada to reproduce, publish, archive, preserve, conserve, communicate to the public by telecommunication or on the Internet, loan, distribute and sell theses worldwide, for commercial or noncommercial purposes, in microform, paper, electronic and/or any other formats.

The author retains copyright ownership and moral rights in this thesis. Neither the thesis nor substantial extracts from it may be printed or otherwise reproduced without the author's permission.

\section{AVIS:}

L'auteur a accordé une licence non exclusive permettant à la Bibliothèque et Archives Canada de reproduire, publier, archiver, sauvegarder, conserver, transmettre au public par télécommunication ou par l'Internet, prêter, distribuer et vendre des thèses partout dans le monde, à des fins commerciales ou autres, sur support microforme, papier, électronique et/ou autres formats.

L'auteur conserve la propriété du droit d'auteur et des droits moraux qui protège cette thèse. $\mathrm{Ni}$ la thèse ni des extraits substantiels de celle-ci ne doivent être imprimés ou autrement reproduits sans son autorisation.
In compliance with the Canadian Privacy Act some supporting forms may have been removed from this thesis.

While these forms may be included in the document page count, their removal does not represent any loss of content from the thesis.
Conformément à la loi canadienne sur la protection de la vie privée, quelques formulaires secondaires ont été enlevés de cette thèse.

Bien que ces formulaires aient inclus dans la pagination, il n'y aura aucun contenu manquant.

\section{Canadä}




\section{Abstract}

Climate change is among the most important ecological problems today. Modelling species' response to these changes has become an important part of understanding and predicting the effects of climatic change. Many models do not incorporate interspecific effects of competition and community, and as a result, fail to generate accurate predictions.

In this study two- and three-species aquatic communities of Lemnoideae were compared along a continuous thermal gradient. Increased community complexity was associated with increased changes in exponential growth rates across a thermal range and average optimal growth temperatures. Species-specific changes in average optimal growth temperature suggest that some species may be more vulnerable to climatic changes as a result of interspecific competition.

This study provides new evidence regarding the effects of community complexity on temperature-dependent growth traits in aquatic plant species. This supports the notion that community dynamics should be considered when generating predictions of species' responses to climatic changes. 


\section{Acknowledgements}

This thesis was completed with the support of many generous people who have provided me with much encouragement, advice and help along the way.

Firstly, I owe much gratitude to my supervisor, Dr. Simons, who provided me with a great deal of support and advice throughout my Master's program. I would also like to thank my committee members: Dr. Sargent and Dr. Sherratt for their input and guidance.

I am very grateful to Bill Hughes, Jake Graham, Mary Compton and the other students who have come through our lab and who have provided me with support.

Finalement, je remercie aussi ma femme Laura Labonté qui n'a jamais cessé de m'encourager, qui m'a aide et supporté lors des mes etudes. Merci aussi à ma famille pour leur support et encouragement. 
Table of contents

iv-v

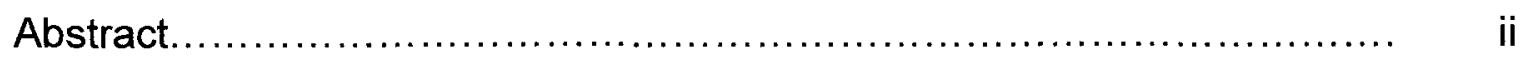

Acknowledgments.............................................................

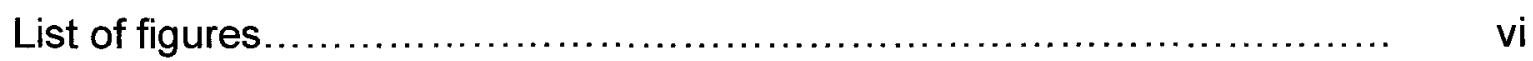

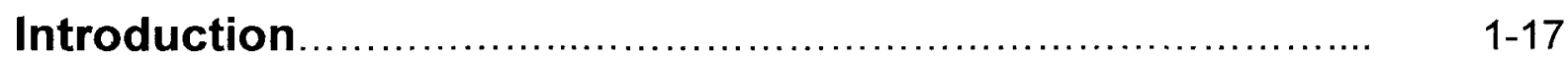

Overview.......................................................... 1

Climate change and species specific responses...................... 2-5

Effect of community on interspecific interactions...................... 5-7

Effect of community on individual species............................. $8-11$

Ecological models of climate change................................. 11-16

Hypotheses and Predictions........................................ 16-17

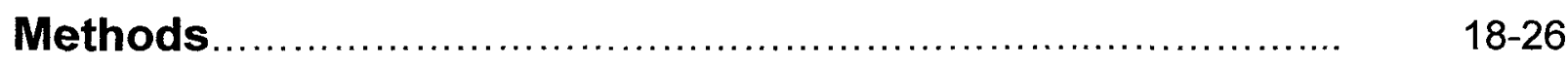

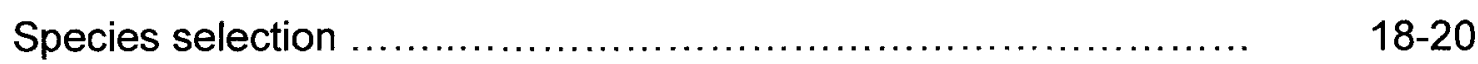

Sample collection............................................... 20-21

Thermogradient................................................. $22-26$

Statistical analyses............................................ $26-28$

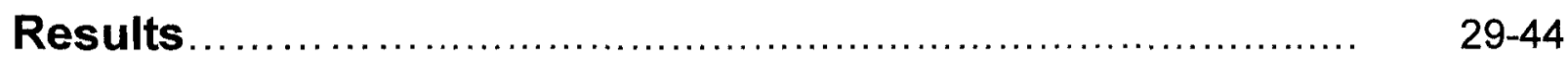

Comparison of temperature-dependent exponential growth rates between isolated populations of Lemnoideae.

Comparison of temperature-dependent exponential growth rates for Lemnoideae species when in isolation and when in a two-species mixed community....

Temperature-dependent exponential growth rates of Lemnoideae in the three-species community compared to when in isolation or two-species communities.

I. S. polyrhiza............................................... $37-38$

II. L. minor.................................................... $38-40$

III. L. trisulca................................................. $\quad 40-42$

Changes in average optimal growth temperature with increased community complexity.... 
Discussion.

References...

57-68 


\section{List of figures}

Figure 1: Water temperature in ${ }^{\circ} \mathrm{C}$ within the aquarium of the thermogradient apparatus as measured at several distances from the cold edge along the apparatus.

Figure 2: Exponential growth rate across a range of temperatures for

L. minor, L. trisulca and S. polyrhiza when grown in isolation.

Figure 3: Exponential growth rate across a range of temperatures for

(a) S. polyrhiza when grown in isolation and in a mixed community with $L$. minor and (b) for $L$. minor when grown in isolation and in a mixed community with $S$. polyrhiza.

Figure 4: Exponential growth rate across a range of temperatures for

(a) L. trisulca when in isolation and in a mixed community with S. polyrhiza and (b) for $S$. polyrhiza when grown in isolation and in a mixed community with L. trisulca.

Figure 5: Exponential growth rate across a range of temperatures for

(a) $L$. minor when grown in isolation and in a mixed community with $L$. trisulca and (b) for L. trisulca when grown in isolation and in a mixed community with L. minor.

Figure 6: Exponential growth rate across a range of temperatures for

$S$. polyrhiza when grown in a three-species community compared to when grown in two-species communities and in isolation.

Figure 7: Exponential growth rate across a range of temperatures for

$L$. minor when grown in a three-species community compared to when grown in two-species communities and in isolation.

Figure 8: Exponential growth rate across a range of temperatures for

$L$. trisulca when grown in a three-species community compared to when grown in two-species communities and in isolation.

Figure 9: Optimal growth temperature for each species when grown in isolation, in a two-species community and in a three-species community. 


\section{Introduction}

\section{Overview}

Global climate change is one of the most significant problems challenging ecologists and evolutionary biologists today. Understanding the extent to which species, communities and ecosystems will be affected is paramount in mitigating and preventing the severe negative effects that may occur (Bell and Collins, 2008; Grieneisen and Zhang, 2011; Simons, 2011). Climatic changes pose a risk not only in terms of extinction through altered habitat, but also through changes in community composition. For example invasive species could become more prevalent and successful following climatic disturbances (Rahel and Olden, 2008). Although modelling how individual species will respond has become an important part of understanding and predicting the effects of climate change, Gilman et al. (2010) suggest that a lack of understanding and incorporation of interspecific effects in climate change models may be an underlying cause in the failure of these models to generate reliable and comprehensive predictions. Furthermore, they suggest that the integration of interspecific effects could greatly improve these models. This thesis provides a basis for understanding interspecific interactions through the use of simple closed communities under controlled laboratory conditions. 


\section{Climate change and species-specific responses}

Over the last 100 years, the global average temperature has been $13.9^{\circ} \mathrm{C}$ (NCDC, 2011) and the average from $2000-2009$ has risen by over $0.6^{\circ} \mathrm{C}$ compared to the average from 1951-1980. The global average is projected to continue rising at a rapid rate (Houghton et al., 2001). Although species have successfully responded to some environmental changes in the past, the rapid rate of recent climate change is a grave concern as species may be unable to respond quickly enough (Bradshaw and Holzapfel, 2006; Bradshaw and Holzapfel, 2008; Harris, 1993; Jump and Penuuelas, 2005; Parmesan, 2006; Schneider and Root, 1998). In a meta-analysis of 143 studies, covering a wide range of species from molluscs to mammals and grass to trees, it was found that there were consistent temperature-related range shifts as a result of climatic change deemed a "fingerprint" of climatic change (Root et al., 2003). In over $80 \%$ of the species examined, the directionality of range shifts was in accordance with what was expected given the physiological constraints of the species (Root et al., 2003). This "fingerprint" of climate change represents a significant impact of global warming that is already discernable in animal and plant populations (Root et al., 2003). Species appear to be undergoing a process known as habitat tracking, where species' ranges shift geographically, thereby remaining within suitable climatic conditions (Dalén et al., 2007). Similarly, in a survey of 53 bird species of Sierra Nevada, changes in climate and bird distributions resulted in species' ranges shifting over time, with 48 of the species tracking their climate niche (Tingley et al., 2009). Additionally, for 50 of the species examined, site-specific occupancy models explained colonization and extinction probabilities better when distance from the climate niche centre was included (Tingley et 
al., 2009). These findings raise questions about whether the rate of climate change will surpass the rate at which species would be able to track suitable habitat (Tingley et al., 2009).

Loarie et al. (2009) examined climate change velocities, the rate at which a climatic range moves geographically, and the rate at which species were tracking these changes. They found that some areas, including mountainous and Mediterranean-types, showed decreased climate change velocities, whereas climate change velocities increased in flooded grasslands, mangroves and deserts (Loarie et al., 2009). Furthermore, within 100 years, only $8 \%$ of global protected areas are projected to have a climate that is habitable by the species they are designed to protect (Loarie et al., 2009). Whereas species may be able to respond to climate change through adaptation, habitat tracking or dispersal to more favourable conditions, these latter options may not be possible under all circumstances, or for all species. For species that lack either the mobility or the dispersive ability to successfully track climatic changes, or have no suitable habitat in which to move, adaptive responses may be the only possible response to climate changes. It has been proposed that evolutionary rescue, the rise of novel mutations or increase in frequency of previously rare alleles, could allow for rapid adaptive changes that allow species to evade extinction (Bell and Gonzalez, 2009). Using yeast populations it was shown that evolutionary rescue is possible but that large population size, high mutation rate, or high genetic diversity were essential in increasing the probability of evolutionary rescue (Bell and Gonzalez, 2009). This suggests that rapid evolution is an important component of the response of small populations to 
environmental change; however, there is likely a very low probability of evolutionary rescue in the majority of populations (Bell and Gonzalez, 2009).

Responses to climate change are expected to be species-specific with varying degrees of sensitivity expressed across multiple species (Thomas et al., 2004). These sensitivities could be predicted using the niche properties and geographical extent of a species (Thuiller et al., 2005). Thuiller et al. (2005) found that there were general patterns in the relationship between species sensitivity to climate change and their ecological properties, including dispersal capability, and that sensitivity could be predicted based on niche properties, such as range size, resource requirements and temperature tolerances. Similarly, Jiguet et al. (2007) studied 71 common breeding bird species in France and examined the role of climate envelope (the range within which a species is able to survive based on climatic conditions of current distribution; Vos et al., 2008), ecological envelope (the range of a species as defined by topographic, climatic, and biological restraints such as soil quality for plants; Coulston and Riitters, 2005) and life history in predicting the response of individual species to climate change. The results of Jiguet et al. (2007) were similar to those of Thuiller et al. (2005) where species with more specialized habitat niches were found to be more sensitive to climatic changes. Additionally, Jiguet et al. (2007) found that life-history traits were significant predictors of sensitivity to climatic changes and that species with the greatest ability to shift spatially and thus remain within preferred climatic conditions would be the least affected by climatic changes. 
Climate change affects species through environmental changes and through secondary effects, such as invasive species or increased abundance of pathogens. A study of the Monteverde harlequin frog (Atelopus sp.) and the golden toad (Bufo periglenes) (Pounds et al., 2006) found that the disappearance of B. periglenes and $67 \%$ of Atelopus resulted from an increase in the pathogenic chytrid fungus Bathrachochytrium dendrobatidis due to global warming. The findings of indirect effects arise not just from increased spread of pathogens, but may also result from changes in parasite hosts (Barnes et al., 1988; Lake and Wade, 2009; Morrison and Morecraft, 2006) or changes in physiological responses as a result of increased temperature (Gifford et al., 1996; Yadugiri, 2010). The findings of these studies demonstrate that there is a need to better understand and predict how species will respond to rapid climate change, and improve our understanding of the factors that affect these responses.

\section{Effect of community on interspecific interactions}

While it would be expected that the most efficient species would outcompete and eliminate less efficient species in a community, this is not necessarily the case as competition between species drives complex interspecific interactions (Lotka, 1922). Understanding how community composition both affects and is affected by interspecific interactions is essential to understanding and predicting long-term trends in species survival (Hanski and Thomas, 1994, Walter et al., 2002). Although previous models for understanding species distribution have used bioclimate envelopes, it has been 
suggested that the validity of these models may be limited (Pearson and Dawson, 2003). Furthermore, factors such as biotic interactions, evolutionary change and dispersal ability should be included to improve the accuracy of models (Pearson and Dawson, 2003). Nevertheless, bioclimate envelope approaches may provide a first approximation.

Previous studies have examined the role of interspecific interactions in determining the distribution and dynamics of populations. Agami and Reddy (1989) examined how Spirodela polyrhiza and Salvinia rotundifolia populations were affected when raised in monoculture compared to when raised in two-species communities. Although Salvinia rotundifolia was not affected by the presence of $S$. polyrhiza; $S$. polyrhiza had a decreased overall population size, but accumulated greater concentrations of Nitrogen and Phosphorous when compared to monoculture populations or mixed populations (Agami and Reddy, 1989). Lankau (2009) examined the coexistence of Brassica nigra when in a community with multiple competitors and found that coexistence was possible only in models that included evolutionary processes. Additionally, genetic variation and resultant evolutionary change allowed for coexistence under a much greater range of ecological conditions (Lankau, 2009).

Connolly and Wayne (2005) found that the most important factors in determining changes in community biomass of a two-species community of annual plants Stellaria media and Poa annua were the differences in growth rate between two species. Additionally, they found that changes in community composition were not significantly affected by the influence of neighbours or fertiliser level. However, this did not diminish the influence of community structure on the intra- and inter-specific competition felt by 
both species (Connolly et al., 1990). Their previous findings had shown that there were significant effects on the biomass of individuals of each species when in a mixed community compared to when in isolation (Connolly et al., 1990).

Community complexity and inter-specific reactions play a significant role in how communities and ecosystems respond to stressors (Vinebrooke et al., 2004). Ecosystem resistance to a single stressor relies on tolerant species that could compensate for more sensitive species. However, multiple stressors may require a greater degree of cotolerance between species. A failure of these inter-specific interactions may increase ecosystem susceptibility to multiple biotic or abiotic stressors (Vinebrooke et al., 2004). However, these interactions do appear to be inherently sensitive to changes in community structure and composition. In a 13-year study of the effect of two salt marsh perennials Monathechloe littoralis and Arthocnemum subterminale on winter annuals and the perennial herb Limonium californicum, strong competitive effects were buffered via direct positive effects among less competitive species (Callaway and Pennings, 2000 ). Additionally the diversity and interdependence of competing species was found to be important in the continued functioning of plant communities (Callaway and Pennings, 2000). These studies demonstrate that the complex interactions between community and individual species may be essential for long-term stability and survival of the community. 


\section{Effect of community on individual species}

To understand how community composition and complexity affects the functioning of communities, it is important to understand how communities and interspecific interaction affects the survival and distribution of individual species. The interactions between species as well as the dispersal and mortality traits of each species can have a significant effect on determining the spatial composition and stability of a community (Tilman, 1994). Tilman (1977) suggested that the coexistence in communities is not just bound in community interactions but also the availability of each species respective required resources. Davis et al. (1998a, b) examined how community composition affected the thermal response of several species of Drosophila, using the abundance and distribution across a range of temperatures. In order to explore the effect of temperature on individual species when under stress from interspecific competition, isolated and mixed communities of Drosophila were used across four distinct temperatures that mimicked a cline of $15^{\circ} \mathrm{C}$ (Davis et al., 1998b). There were distinct differences in abundance and range size for species when in a community compared to when in isolation (Davis et al., 1998b). Furthermore, the outcomes of pairwise competitions were strongly dependent on temperature with $D$. subobscura eliminating $D$. melanogaster or $D$. simulans at low temperatures and in turn was eliminated at high temperatures by the other species (Davis et al., 1998b). The addition of the parasitoid Leptopilina boulardi had a strong direct effect on host assemblages at high temperatures where the parasitoid was present but the effect was indirect, and decreased at low temperatures where the parasitoid was scarce (Davis et al., 1998b). While the findings of Davis et al. (1998b) reinforce the effect of temperature on species 
distributions, Chesson (1994) had previously suggested that interspecific competition in variable environments can have a significant effect on the outcome of competition. They proposed that the competition involved both a component that is independent of environmental fluctuations and a dependent component that can have a significant effect on the outcome of competition (Chesson, 1994). When simulated global warming was included in the model system, there were complex often counter-intuitive effects on distribution and abundance, including reversal of species' relative abundance (Davis et al., 1998a). Since dispersal and species interactions strongly influence both range and abundance, models that fail to incorporate these factors will likely result in incorrect predictions (Davis et al., 1998a, 1998b).

A review of 668 published studies explored the possibility that drivers of climate change can alter competitive interactions between plants and animals and exert multitrophic effects on food webs, pathogen infection, mutualisms, herbivory and predation (Tyliankis et al., 2008). Among the drivers and biotic interactions included in the review, there was a great deal of variability found in the magnitude and direction of effects of any driver on any biotic interaction (Tylinakis et al., 2008). These findings suggest that biotic and abiotic interactions can alter the direction and magnitude of the effect of global warming on biotic interactions (Tyliankis et al., 2008). Fox and Morin (2001) similarly proposed that intraspecific competition and/or predator-prey interactions should buffer environmentally produced changes in density-dependent growth rates whereas interspecific competition should magnify sensitivity to changes. They tested these hypotheses with multiple two-species competitions and found that although intraspecific interactions did buffer species densities against temperature changes, interspecific 
interactions did not have a significant effect (Fox and Morin, 2001). They also found weak effects of temperature change on species density regardless of the presence of other species. Fox and Morin (2001) suggested that natural populations may be buffered against directional environmental change, although there was no incorporation of the effect of climate change on the competitive interactions between species in models of the time. Furthermore, it has also been suggested that the presence of herbivory may help direct community dynamics and help control community composition. The incorporation of large herbivores and the evolutionary history of grazing in a grassland community can result in significantly improved predictions of composition and competitive interactions (Milchunas et al., 1988). A study of duckweed (Lemna minor) and a herbivorous moth (Cataclysta lemnata) showed that global warming may reduce rather than promote herbivory (Van der Heide et al., 2006a). An increase in temperature led to a sigmoidal increase in $C$. lemnata grazing rates and a linear increase in $L$. minor growth rates, as a result the increased vegetative growth rate compensated for the grazing rate and led to a decreased overall grazing pressure (Van der Heide et al., 2006a). However, in a five-year study of the effect of herbivores on tundra plant communities, it was found that the presence of herbivores prevented a change in community composition as a result of climate change (Post and Pedersen, 2008). These findings suggest that whereas climate changes can alter community composition, biological interactions in these communities may be able to mitigate these effects.

A recent study into the effects of temperature on intraspecific competition and population dynamics showed that increased temperature resulted in decreased resource density due to strong intraspecific competition among consumers (Ohlberger et al., 
2011). Additionally, the consumer population dynamics shifted from a stable equilibrium to a competition-driven generation cycle that was dominated by recruits (Ohlberger et al., 2011). Furthermore in the model populations, maximum age decreased and there were significant increases in the proportion of younger and smaller fish (Ohlberger et al., 2011). It was concluded that global warming may increase competition, favour smaller size classes and induce regime shifts that destabilize population and community dynamics (Ohlberger et al., 2011). These studies demonstrate that the complex interspecific interactions that arise in mixed communities may result in unexpected or counterintuitive outcomes when compared to species in isolation.

\section{Ecological models of climatic change}

Previous models, which use the climate envelope approach, mapped the current distribution of species in climate-space and then shifted the position of species according to movement in the climate-space (Beerling, 1993; Jeffree and Jeffree, 1996; Porter, 1995; Rogers and Randolph 1993; Scott and Poynter, 1991; Sutherst et al., 1995). The main criticism of these models is that interspecific interactions are not reflected and that these interactions may be significantly altered or disrupted by climate change (Brubaker and McLachlan, 1996; Connel, 1961; Davis, 1981; Davis, 1986; Davis, 1998a, b; Graham, 1992; Jeffree and Jeffree, 1996; Valentine and Jablonski, 1993; Walter and Patterson, 1994). A review of predictive habitat models (including conceptual models, generalized linear models, neural networks, ordination and classification methods, Bayesian models, locally weighted approaches, environmental models and even combinations of these) found that across all of the models examined, 
key topics relating to limitations appeared repeatedly and one of the most important of these was 'biotic interactions' (Guisan and Zimmermann, 2000). It was found that the incorporation of biotic interactions and in particular, competition must be addressed in future static and dynamic species distribution models to improve accuracy and reliability of predictions. Although models provide a good estimate of species richness, they still fail to include the effect of interspecific interactions (Pineda and Lobo 2009). Since model predictions do not take biotic interactions into account, they inevitably tend to approach a potential rather than realised distribution of species. These predicted distributions therefore provide an unreliable representation of reality (Pineda and Lobo, 2009).

In exploring the role that climate, habitat and species co-occurrence play in the distribution of small mammals, it was found that when biotic predictors were included in models, climate alone became the dominant predictor in explaining species distribution (Rubidget et al., 2011). Despite this, climate alone was not always adequate for predicting the distributional changes observed in the species examined (Rubidge et al., 2011). Although distribution models are useful in understanding potential responses to climate change, a better understanding of how changes in species-environment correlations change through time can limit the predictive performance of models. A study of the effect of climate change on three species of chipmunk, Tamias alpinus, Tamias senex and Tamias speciousus, showed that a multi-species model which examined interactions between species had a significantly greater predictive capacity when compared to models that examined each species individually (Rubidge et al., 2011). These findings and others have suggested that including biotic interactions will allow for 
the development of a more complete mechanistic understanding of both the direct and indirect effects of climate change on individual species (Graham et al., 2004; Guisan and Zimmermann, 2000; Pineda and Lobo, 2009; Rubidge et al., 2011). It is surprising, given the apparent need for incorporating biotic processes into predictive models, that even the most recent reviews have found that the integration of biotic process is not occurring (Rubidge et al., 2011).

It is possible that the lack of biotic interactions in predictive models is due to a lack of studies examining these interactions (Ibanez et al., 2006). There is a pressing need for further experimental and observational studies on the interspecific effectsincluding competition-and the effect of temperature on these interspecific effects to shift the emphasis of models from predicting extinction to identifying vulnerabilities (Ibanez et al., 2006). However, the complications and complexities of examining interspecific interactions across a temperature range have resulted in limitations, even in some of the best previously published studies. Two of the more cited studies of competition across a range of temperatures by Davis et al. (1998a, b), had limitations in distribution of temperature across the experiment range. The methodology used by Davis et al. (1998a, b) involved four incubators with eight linked cages between them, two per incubator, with incubators set a $10,15,20$ and $25^{\circ} \mathrm{C}$ in sequential order. Although this does provide a large difference in temperature, there was no continuous gradient; instead it was a low-resolution categorical division of temperatures. A similar low-resolution temperature range has been seen in multiple studies that examined the effect of temperature (Van der Heide et al., 2006b; Villalpando et al., 2009). Multiple studies have emphasized the need for fine-grained environmental variation in studies of 
performance and selection as these gradients mirror those found in nature (Froeschke et al., 2010; Kingsolver and Gomulkiewicz, 2003; Li et al., 2010; Miznera and Meszéna, 2003; Simons and Wagner, 2007; Vonlanthen et al., 2009).

I address this need for fine-grain variation through the use of a thermogradient apparatus to simulate a range of temperatures. Rather than depend on distinct regions of differing temperature, this apparatus provides a continuous gradient with a linearrelationship between position and temperature along the length of the apparatus. The apparatus has been previously used successfully to examine continuous norms of reaction for seed germination (Simons and Wagner, 2007). An additional criticism of the system used by Davis et al. (1998a, 1998b) was that dispersal within the system could result in biases in the true range of species because unsuitable areas could still be populated due to dispersal from more favourable habitat (Bonte et al., 2009; Griffiths et al., 2010). The model organisms used for my study are members of the subfamily Lemnoideae, previously referred to as the Lemnacaea, in the family Araceae (Cabrera et al., 2008). Lemnoideae, also known as duckweed, are small, floating or submerged aquatic plants whose population normally expands by the recruitment of asexual propagules (Landolt, 1986). As non-motile plants, this reduces the error that could arise from dispersal.

There are several additional important properties of the Lemnoideae that make them well suited as a model system for exploring the evolution, adaptation and ecology of higher plants. They are true flowering plants and also have the benefit of rapid growth, with some species able to double in quantity in less than three days (Lemon et al., 
2001). They are small and structurally simple (Bhalla et al., 1973), and can be grown under controlled environmental conditions (Bhalla et al., 1973). Reproduction of Lemnoideae is often vegetative but there are several species in which sexual reproduction is known to occur and can be triggered in laboratory settings (Bhalla et al., 1973, Cleland and Tanaka, 1982). Lemnoideae have also been used to great success in numerous morphological, physiological, and biochemical studies (Appenroth, et al., 1996; Appenroth, 2002; Appenroth and Ziegler, 2008; Hillman, 1959a, b, c; Hillman, 1961a,b; Krajncic and Nemec, 2003; Song et al., 2006; Takimoto et al., 1994; van der Heide, 2006b; Vasseur, 1993).

The choice of Lemnoideae as a model system is also facilitated by several life history and descriptive studies done on these organisms (Arber, 1920; Hillman, 1961; Kandeler, 1989). Furthermore, there have been previous studies of several Lemnoideae species examining the effect of intra- and inter-specific competition from different Lemnoideae and other aquatic plants. However, these studies were performed at a single temperature, were observational studies of natural populations or did not examine the effect of temperature. Competitions between Lemna gibba with Elodea nuttallii demonstrated $E$. nuttallii was able to significantly affect the nutrient conditions in the water column and at lower nutrient levels, could substantially deny nutrients to $L$. gibba and decrease its growth rate (Szabo et al., 2010). For L. minor, it has been found that as density increases, a non-linear relationship between density and intraspecific competition could force negative growth rates at high densities, effectively capping density levels (Driever et al., 2005). However increases in air temperature caused an increase in maximum density, suggesting that environmental changes can cause 
directional shifts in density-dependent growth rates (Driever et al., 2005). A study of small free-floating aquatic plants found that Spirodela punctata was competitively inferior to Salvinia minima in Florida during the summer (Dickinson et al., 1998). The use of Lemnoideae in physiological and ecological research has resulted in a continual and extensive development of methodology for the growth, maintenance, and manipulation of Lemnoideae in a laboratory setting (Bowker et al., 1980; Hillman 1959a, b; Hillman 1961a, b; Krajncic and Nemec, 2003; Strasser, 1971; Takimoto et al., 1994).

There is a strong demonstrated need for experimental studies to examine the effects of community complexity on individual species responses. Specifically, on how temperature affects the growth response of individual species, and how these growth responses-_including optimal temperature-are affected by interspecific interactions as community complexity changes (Gilman et al., 2010; Graham et al., 2004; Guisan and Zimmermann, 2000; Pineda and Lobo, 2009; Rubidge et al., 2011). In this study, a continuous temperature gradient and non-motile species are used to address the need for fine-grained studies that more closely simulate natural environmental gradients (Froeschke et al., 2010; Kingsolver and Gomulkiewicz, 2003; Li et al., 2010; Mizera and Meszéna, 2003; Simons and Wagner, 2007; Vonlanthen et al., 2009).

\section{Hypotheses and Predictions}

This study has several objectives. First, to assess the extent to which the growth rate is affected by a single competitive species across a continuous temperature gradient, whereby I hypothesize that the exponential growth rate will be significantly 
affected by the presence of a competing species. I predict that the exponential growth rate of the focal species will decrease in the presence of a single competitor compared to isolated populations across the entire thermal range. The second objective is to examine how growth rate is affected by two competing species. I hypothesize that the average exponential growth rate of a focal species will be significantly affected by the presence of two competing species. I predict that this effect will result in decreased growth rates at all temperatures compared to populations both in isolation and in twospecies communities. Lastly, this study aims to determine if optimal temperature of a focal species is affected by the presence of two competing species. I hypothesize that there will be a significant change in optimal growth temperature as a result of both a single and two competing species. I predict that the directionality of the change in optimal growth temperature will be conserved although the magnitude of the change in optimal temperature will be greater as community complexity increases.

Although the effect of climate change has been examined and modelled using the response of isolated species, a lack of interspecific interactions may be decreasing the accuracy of these models. This study attempts to address this limitation by providing empirical evidence of the effect that community complexity has on species-specific temperature dependent performance. This is an essential first step in exploring, understanding and integrating interspecific and community level interactions for use in climate change models. 


\section{Methods}

\section{Species selection}

Species from the subfamily Lemnoideae were used as model organisms to simulate diverse communities of competing organisms. In the area surrounding Ottawa there are four commonly found species of Lemnoideae: Spirodela polyrhiza, Lemna minor, Lemna trisulca and Wolffia borealis. Of these species $W$. borealis was judged to be too small for the purposes of this study, having a length of $0.7-1.2 \mathrm{~mm}$ and an average width of $0.3 \mathrm{~mm}$ (White and Wise, 1998). The small size of $W$. borealis made it difficult to manipulate in mixed communities and individuals would often pass through filters used to collect individuals for examination. As a result, S. polyrhiza, L. minor and L. trisulca were used in this study. S. polyrhiza, also known as greater duckweed, is found throughout North and Central America, Europe, Africa, Asia and Australia and to a limited extent South America (Jacobs, 1947). S. polyrhiza can be identified by having 516 roots, 7-12 veins and is flattened, and orbicular-ovate in shape and can be up to $10 \mathrm{~mm}$ in width (Fernald, 1950). Whereas the upper surfaces are green, the ventral surface is often reddish-purple in colour. Commonly found in freshwater ponds, marshes and quiet streams, they are also found in shallow standing water surrounding larger rivers. Reproduction is mostly clonal, with daughter fronds being produced from two lateral pouches on either side of the basal end. Fronds are often found in groups of 2-5 connected by a single vein between fronds (Fernald, 1950). S. polyrhiza can also produce smaller, rootless dark green or brown coloured dormant turions especially during the fall (Jacobs, 1947). Turions are high in starch and are denser than water; as a result, they settle to the bottom of the water body (Landolt, 1986; Landolt and Kandeler, 
1987). Turions overwinter at the sediment surface and remain there until growth conditions are more suitable, at which point the starch is broken down and the turion rises to the surface and produces a normal daughter frond (Appenroth, 2008). While flowering is possible in S. polyrhiza, it was not observed throughout the duration of the laboratory experiments.

L. minor, also known as lesser duckweed, is a floating species of duckweed that often forms large heavy mats across the surface of water bodies in which it is found. Individual plants are flattened, sub orbicular to elliptic ovate in shape, approximately 3$4 \mathrm{~mm}$ long, $1-2 \mathrm{~mm}$ wide, have three veins and have a single root which can exceed $15 \mathrm{~cm}$ in length (Clark, 1979; Den Hartog and van der Plas, 1970). Clonal reproduction occurs from budding pouches at the basal end and plants are often found in connected groups of 2 to 5 (Fernald, 1950). Flowering is known to occur (Hillman, 1959) but like in S. polyrhiza, was not observed during the course of these experiments. Found throughout North America preferring cool temperate regions with relatively mild winters, L. minor is also found in Western Europe, Africa and Atlantic Islands and has been introduced to Australia and New Zealand (Den Hartog and van der Plas, 1970).

In contrast to both L. minor and S. polyrhiza, L. trisulca is a submersed aquatic plant whereby individuals grow just below the surface of the water body and move to the surface only when flowering (Clark, 1979; Den Hartog and van der Plas, 1970).

Submersed plants are oblate to elliptic in shape $4-10 \mathrm{~mm}$ long (excluding the stipe) and taper down at the base to a long slender stipe that is often connected to the mother frond (Fernald, 1950). Flowering plants however are often shorter and thicker with a 
serrate margin and shorter stipe (Den Hartog and van der Plas, 1970). It is found in freshwater creeks, ponds and marshes (Clark, 1979). Clonal daughter fronds are produced from 2 lateral pouches at either side of the basal end above the stipe and fronds are often found in long chains composed of 8-30 connected daughter fronds (Clark, 1979). Submersed plants can be found underneath populations of $L$. minor or $S$. polyrhiza commonly entangled throughout the roots of the floating plants above. $L$. trisulca can be found throughout North America spreading as far north as Alaska as well as throughout Europe, Africa, Asia and Australia (Den Hartog and van der Plas, 1970).

While $S$. polyrhiza has been used extensively and $L$. minor to a lesser degree in physiological research, there has been much less work performed with $L$. trisulca.

\section{Sample collection}

Species were collected from four locations: Mud Lake $\left(45.371202^{\circ},-75.794721^{\circ}\right)$; the NWRC Parking Lot Pond $\left(45.38427^{\circ},-75.690705^{\circ}\right)$; Petrie Island $\left(45.502918^{\circ}\right.$, 75.494614 ${ }^{\circ}$ ); and Lac Cromwell- part of the Station de Biologie des Laurentides $\left(45.987271^{\circ},-74.002876^{\circ}\right)$. Samples were collected by hand and stored in water from their native pond during transport to Carleton University. Once at Carleton, plants were first filtered from the pond water to remove any remaining large particles then were rinsed repeatedly with distilled water to remove any remaining small particles. Once samples had been cleaned, they were placed in $500 \mathrm{~mL}$ Erlenmeyer flasks with $150 \mathrm{~mL}$ of growth medium. Initially, plants were stored in a 0.5 concentration of standard Hutner's 
solution. For these experiments half concentrations of nutrient medium were used as higher concentrations were found to result in increased algal growth. Half concentrations have been commonly used in many previous studies of Lemnoidaea (e.g. Bassi and Sharma, 1993; Ben-Tal and Cleland, 1981; Glandon and McNabb, 1978; Ornes et al., 1991; Shi et al., 2011). However, it was observed that this rapidly resulted in the deterioration of the plant stocks and was subsequently replaced with Hoagland medium at 0.5 concentration (final molecular concentration: $2.50 \mathrm{mM} \mathrm{KNO}_{3}, 0.868 \mathrm{mM}$ $\mathrm{CA}\left(\mathrm{NO}_{3}\right)_{2} \times 4 \mathrm{H}_{2} \mathrm{O}, 0.151 \mathrm{mM} \mathrm{FeSO}_{4} \times 7 \mathrm{H}_{2} \mathrm{O}, 4.95 \mathrm{mM} \mathrm{MgSO}_{4}, 0.500 \mathrm{mM} \mathrm{NH}_{4} \mathrm{NO}_{3}, 23.1 \mu \mathrm{M}$ $\mathrm{H}_{3} \mathrm{BO}_{3}, 2.91 \mu \mathrm{M} \mathrm{MnCl}{ }_{2} \times 4 \mathrm{H}_{2} \mathrm{O}, 0.215 \mu \mathrm{M} \mathrm{ZnSO}{ }_{4} \times 7 \mathrm{H}_{2} \mathrm{O}, 0.100 \mu \mathrm{M} \mathrm{CuSO}_{4} \times 5 \mathrm{H}_{2} \mathrm{O}, 0.220 \mu \mathrm{M}$ $\mathrm{H}_{3} \mathrm{MoO}_{4} \times \mathrm{H}_{2} \mathrm{O}, 0.164 \mu \mathrm{M} \mathrm{Na} 2 \mathrm{MoO}_{4} \times 2 \mathrm{H}_{2} \mathrm{O}$, and $\left.0.270 \mathrm{mM} \mathrm{KH}_{2} \mathrm{PO}_{4}\right)$. Although Lemna trisulca underperformed when in Hoagland solution, after testing several variants of Hoagland solution and Kuhl solution it was found that Kuhl was a superior medium for growth of $L$. trisulca and as a result, was used at one half concentration in all subsequent experiments involving L. trisulca. Final Molecular concentrations for Kuhl medium, when diluted to half concentrate were: $0.15 \mathrm{mM} \mathrm{KH}_{2} \mathrm{PO}_{4} 1 \mu \mathrm{M} \mathrm{Ca}\left(\mathrm{NO}_{3}\right)_{2}, 8 \mathrm{mM}$ $\mathrm{KNO}_{3}, 1 \mathrm{mM} \mathrm{MgSO}_{4}, 5 \mu \mathrm{M} \mathrm{H}_{3} \mathrm{BO}_{3}, 12 \mu \mathrm{M} \mathrm{MnCl}, 0.4 \mu \mathrm{M} \mathrm{Na}_{2} \mathrm{MoO}_{4}$, and 25 $\mu \mathrm{M}$ FeEDTA. The medium was replenished every three days. Once a week plants were removed from the flask, and rinsed repeatedly with distilled water to remove algae while vessels were cleaned. Vessels were rinsed and filled with hot water to destroy residual algae. Vessels were then rinsed a minimum of three times with distilled water and filled with fresh medium before plants were returned to the flask. In order to control for maternal effects during competition treatments, all species were grown on a common 0.5 concentrate Kuhl medium for a minimum of two weeks. 


\section{Thermogradient}

All experimental work with both isolated populations and mixed communities was performed on a thermogradient plate. The thermogradient apparatus is composed of two sections, the first section is a 114.5 by 42 by $4.5 \mathrm{~cm}$ aluminum block through which two counter current cold water lines run through at one end and two counter current hot water lines run through the opposite end. Cold water was provided by a Neslab Endocal RTE-9 refrigerated circulating bath and hot water was supplied by an RMT Lauda RM6 Lauda super. On top of this was a custom-built aquarium apparatus constructed of aluminum and Plexiglas. The aquarium was permanently divided into two rows, which could each be further divided into three rows using removable barriers for a total of six rows. Fischer Scientific vacuum pump oil (Cat. Number WNBAD220) was used as a thermal conductive medium between the aluminum block and the aquarium. The oil ensured heat transfer between the aquarium and the thermal gradient, and ensured continuous contact and even heat distribution across the aquarium. The system was lit throughout all of the competitions using an overhead suspended fluorescent light with two Sylvania Octron FO32/T41/ECO $4100 \mathrm{~K} 32 \mathrm{~W}$ bulbs on a GE plug-in mechanical timer set to a 16 hour light/8 hour dark day. 


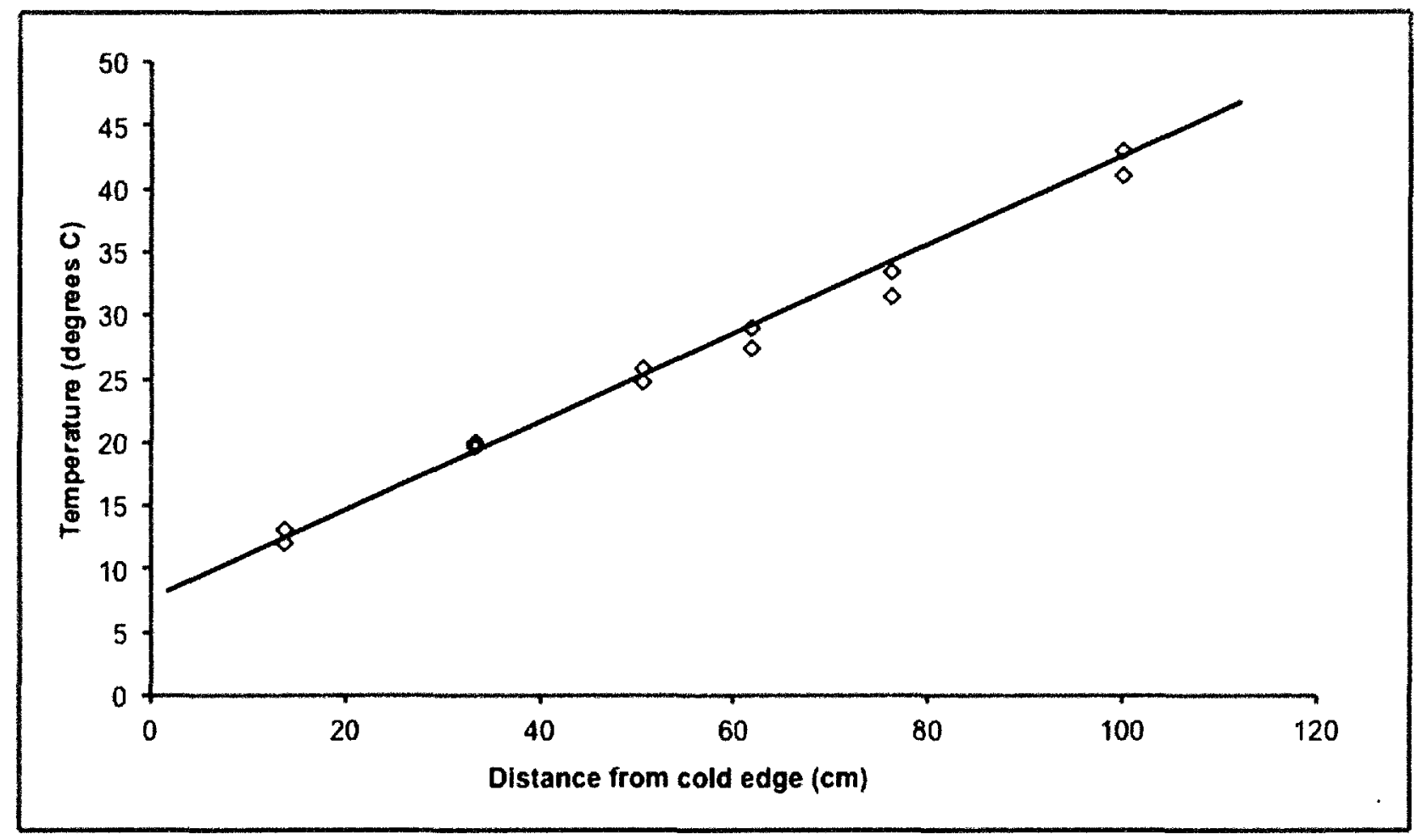

Figure 2: Water temperature in ${ }^{\circ} \mathrm{C}$ within the aquarium of the thermogradient apparatus as measured at several distances from the cold edge along the apparatus.

Before each experimental run on the thermogradient, the aquarium was rinsed with distilled water and dried completely. The aquarium was then cleaned with $70 \%$ ethanol. Additionally, the aquarium was lifted and the vacuum pump oil was cleaned off of the thermogradient and replaced to ensure optimal thermal conduction during all runs. Before adding plants, the aquarium was filled with $12 \mathrm{~L}$ in each of the two permanent rows with $1 / 2$ concentrate Kuhl medium. In addition to this, a small secondary reserve was maintained using a $2 \mathrm{~L}$ Erlenmeyer flask with an automated flow control system to allow for controlled release of reserve medium into the aquarium to help moderate water levels. Due to very low humidity in the laboratory, evaporation was known to be a problem and the aquarium could evaporate as much as $3 \mathrm{~L}$ per day of medium. In order to control for this evaporative loss, a structure was built which enclosed the thermogradient, the medium reservoir and a Honeywell humidifier with automated 
humidity settings. This allowed for the thermogradient to be maintained at a much higher humidity than the surrounding room, greatly lowering evaporative loss and prevented excess drying of the aquarium. Medium was replenished twice a week and replaced once a week. When replacing medium, the old medium was drained away via siphon and new medium added to the thermogradient without the removal of the plants. Within the aquarium, plastic seedling tray inserts were used to control plant movement in the medium and resulted in each row of the aquarium being divided into 18 separate bins. Holes in the bottom of each bin allowed for continuous circulation of nutrient medium throughout the system.

Once the thermogradient had been prepared, plants were introduced into the aquarium from the maintenance populations. While plants from all locations sampled had been used in preliminary work such as determining the best nutrient medium, the majority of the plants used on the thermogradient were progeny of samples taken from Mud Lake. Plants were measured with electronic sliding callipers before introduction in the aquarium to ensure that all bins received plants with the same total surface area, and in the majority of cases, the same number of individuals. Plants were measured along both the long and short axis and then these values were used to calculate the surface area assuming an oval shape. Measurements were made to the nearest $0.01 \mathrm{~mm}$. This meant that each bin in which a species was found had the same surface area of that species regardless of whether the species was alone or in competition. Bins in which competition was occurring consequently had a greater total surface area of 
plants but the same surface area of individual species as bins in which those species were growing in isolation.

Four runs were performed on the thermogradient; three runs involving a twospecies community and a run involving a three-species community. For the two-species community, there were two replicates for the community at each temperature point and two bins for each individual species grown concurrently in isolation. For the threespecies community, there were three replicates for the community at each temperature point and a single cell for each individual species grown concurrently in isolation. For each experimental run, plants were grown on the thermogradient for a total of 3 weeks with medium and plants maintained as stated above. The period of three weeks was chosen to ensure that all experiments could be completed within the required time frame additionally this same experimental duration had been used in previous studies of Lemnoideae, recently by Njambuya et al (2011). At the end of three weeks, plants from each bin were removed, measured using a sliding electronic calliper and either returned to the general populations in the lab or were disposed of. For several runs, plants that had been grown in isolation were dried for twenty-four hours and weighed to determine species-specific temperature dependent relationships between surface area and biomass. For plants that were to be weighed, they were removed from the thermogradient and rinsed in distilled water before being placed in weigh boats which had been weighed beforehand and weighed wet. While it was found that mass would stop changing after less than eight hours in a VWR drying oven, drying was continued for a minimum of twelve hours to ensure uniform results. Following drying, plants and weigh boat were weighed once more before plants were removed and the weigh boats 
were weighed a second time when empty. Dry masses were compared to surface area and this conversion factor was used to convert surface area to biomass across treatments.

\section{Statistical analyses}

Surface areas of plants from each bin for all treatments were recorded in Microsoft Excel. The temperature dependant surface area to biomass relationships were calculated in Excel as were the relationships for temperature to distance along the thermogradient. Once the surface area values had been converted into biomass, the change in biomass over the experiment were calculated using the following exponential equation:

$$
G=\frac{\ln \left(m_{f}\right)-\ln \left(m_{i}\right)}{T}
$$

Where $G$ is the temperature dependent exponential growth rate, $m_{f}$ is the final biomass, $m_{i}$ is the initial biomass and $T$ is the duration of the experimental run. Preliminary analysis of the data was performed in PASW 18 (18.0.0). In some bins, fronds had stuck to the side of the bin and dried out, abnormally reducing the population; or there had been an apparently abnormal growth. These data points were suspected to be outliers. In PASW, for each individual treatment, datasets were examined for outliers and a total of 16 data points were removed. After removing outliers, 562 data points remained and were distributed amongst the experimental runs as follows. For the run with a community of $L$. minor and S. polyrhiza there were 30 measurements of $S$. polyrhiza in isolation and 33 when in the community. For $L$. minor, there were 34 measurements made when in the community and 31 when in isolation. For the community of $S$. polyrhiza and $L$. 
trisulca there were 34 measurements of S. polyrhiza when in isolation and 30 when in competition whereas for $L$. trisulca there were 30 and 29 for isolation and competition respectively. When the experimental run included $L$. minor and $L$. trisulca, $L$. minor had 33 measurements for both when in the community and when in isolation while there were 19 measurements of $L$. trisulca alone and 25 when in the community. For the three species community, there were 17 measurements each of $L$. trisulca and $L$. minor when in isolation and 18 of S. polyrhiza. There were 46 measurements of L. trisulca in the three-species community, 51 of $L$. minor and 52 of $S$. polyrhiza. Curve estimation in PASW was used to optimize polynomial curves that were fitted to observations of species when in isolation and when in two or three species communities. Of the multiple options, including linear, second and third order polynomials, exponential, and logarithmic curves, it was found that second-degree polynomials were the only curve that was significant across all treatments and for all species. For example, for the population of $L$. minor when in isolation it was found that the equations were ranked in the following order by the adjusted $R^{2}$ : Second-order polynomial $(0.360)$, Inverse (0.342), third-order polynomial (0.340), logarithmic (0.305) and lastly linear $(0.256)$. Since the growth rate variable contained negative values in this case; compound, power, S, growth, exponential, and logistic curves could not be fit. Second-order polynomials were therefore used for analysis. Differences between treatments were examined using comparative non-linear regressions and ANCOVA (analysis of covariance) tests in Graphpad Prism 5 following methods outlined by Graphpad, and previously described (Bell and Collins, 2008; Hornun et al., 2003; Motulski, 1999; Schröer et al., 2009; Theo et al., 2000; Wu et al., 2000). For each two-species community treatment, the non-linear regression and ANCOVA compared the exponential growth rates observed of 
populations in the community to those of the species when in isolation. Non-linear regression fit the following model to each dataset:

$$
G=A+B \times T+C \times T^{2}
$$

Where $G$ is the temperature dependent exponential growth rate; $A, B$, and $C$ are populations specific coefficients and $T$ is temperature. The regression curve for each population was compared using and extra sum-of-squares $\mathrm{F}$ test that compared the independent fit of each population with a global fit. Nonlinear regression and ANCOVA were used to determine whether or not there was a significant difference in the growth rate between two populations. For three-species communities, exponential growth rates from the populations in the three-species community were compared with those of isolated populations and those in two-species communities. Optimal temperatures were calculated from the second-order polynomial fit to the data. Since second-degree polynomials had been fit to the temperature dependent growth rate curves, there is a single point at which this curve is maximized. The maximum point of a second order polynomial can be determined using the first derivative of the curve. The temperature at which the first derivative is zero is the point of the maximum in the curve, and the optimal growth temperature. Determining optimal temperatures is essential in assessing changes in the thermal niche and growth temperature of a population. 


\section{Results}

The results of this study show that community complexity can affect the growth rate and optimal growth temperature of aquatic plant species. In comparing two- and three-species aquatic communities changes in both exponential growth rate and optimal growth temperature were more significant as community complexity increased.

\section{Comparison of temperature-dependent exponential growth rates between isolated populations of Lemnoideae}

In order to better understand the inherent differences between the exponential growth rates of $L$. minor, L. trisulca and $S$. polyrhiza, isolated populations of each species, grown concurrently alongside the three-species community experiment, were compared across a range of temperatures. Non-linear regression revealed significant differences between the curves of exponential growth rate across a range of temperatures when comparing all three species $\left(p<0.001\right.$, d.f. $=47, F=9.617, R^{2}=$ $0.4886)$ as well as when comparing just those of $L$. minor to $L$. trisulca $(p<0.001$, d.f. $=$ $\left.30, F=13.48, R^{2}=0.3370\right), L$. minor to $S$. polyrhiza $(p=0.039)$ and $S$. polyrhiza to $L$. trisulca $\left(p=0.001\right.$, d.f. $\left.=31, F=9.949, R^{2}=0.5300\right)$. However, there was no significant difference in the optimal growth temperature between species when in isolation (all $p>0.05$ ) (Figure 2). 


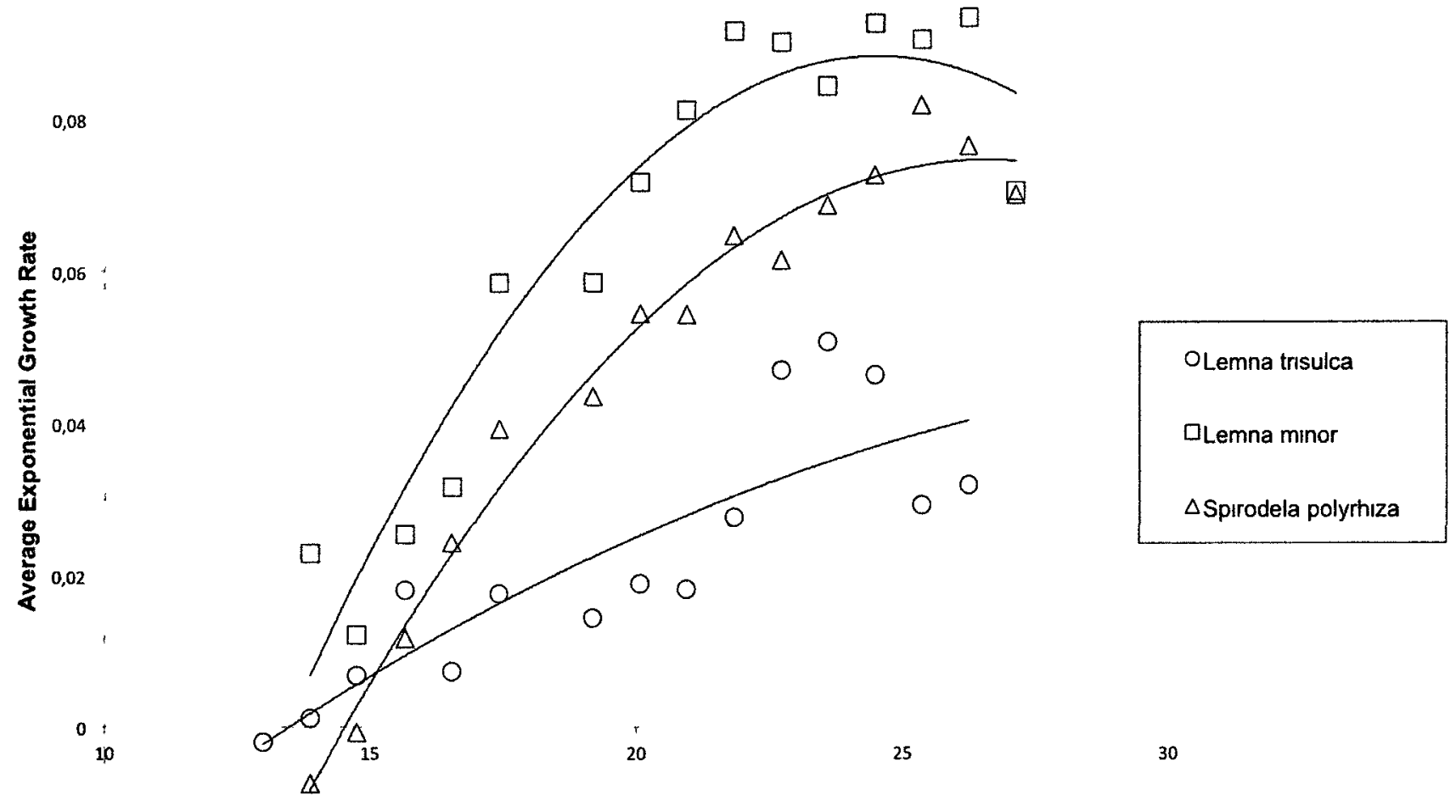

$-0,02$

Temperature $\left({ }^{\circ} \mathrm{C}\right)$

Figure 2: Exponential growth rate across a range of temperatures for $L$. minor, $L$. trisulca and S. polyrhiza when grown in isolation. For curve presentation (but not for data manipulation) at each temperature interval, the values of the two neighbouring rows were added to the value of the row at that data point such that each temperature interval represents a bin of much larger size. The exponential growth rate was then calculated for each of these temperature points and this was plotted for graphs and figures.

\section{Comparison of temperature-dependent exponential growth rates for Lemnoideae species when grown in isolation and in a mixed two- species community}

To determine whether the species that are part of a mixed community can alter the effect of community complexity on exponential growth rate across a range of temperatures, multiple mixtures of two-species communities were used.

L. minor and S. polyrhiza are both surface dwelling aquatic plants. I compared the exponential growth rate of each species across a range of temperatures both when 
plants were grown in isolation and in mixed communities. Using both a non-linear regression and an ANCOVA, the curves of exponential growth rate across a range of temperatures for $S$. polyrhiza were not significantly different (regression: $p=0.463$, d.f. $=$ $59, F=0.8693, R^{2}=0.2582 ;$ ANCOVA $p=0.101$, Mean Difference (M.D. $)=-0.010$, Standard error $(S . E)=$.0.006 ) when grown in isolation and in the mixed community with L. minor (Figure 3a). Additionally, there was not a statistically significant difference (regression: $p=0.364$, d.f. $=61, F=1.082, R^{2}=0.2260 ;$ ANCOVA: $p=0.545, M . D .=-$ 0.004$, S.E. $=0.007)$ between the exponential growth rate vs. temperature curve for $L$. minor when grown in isolation compared to that of when in a mixed community with $S$. polyrhiza (Figure 3b): 


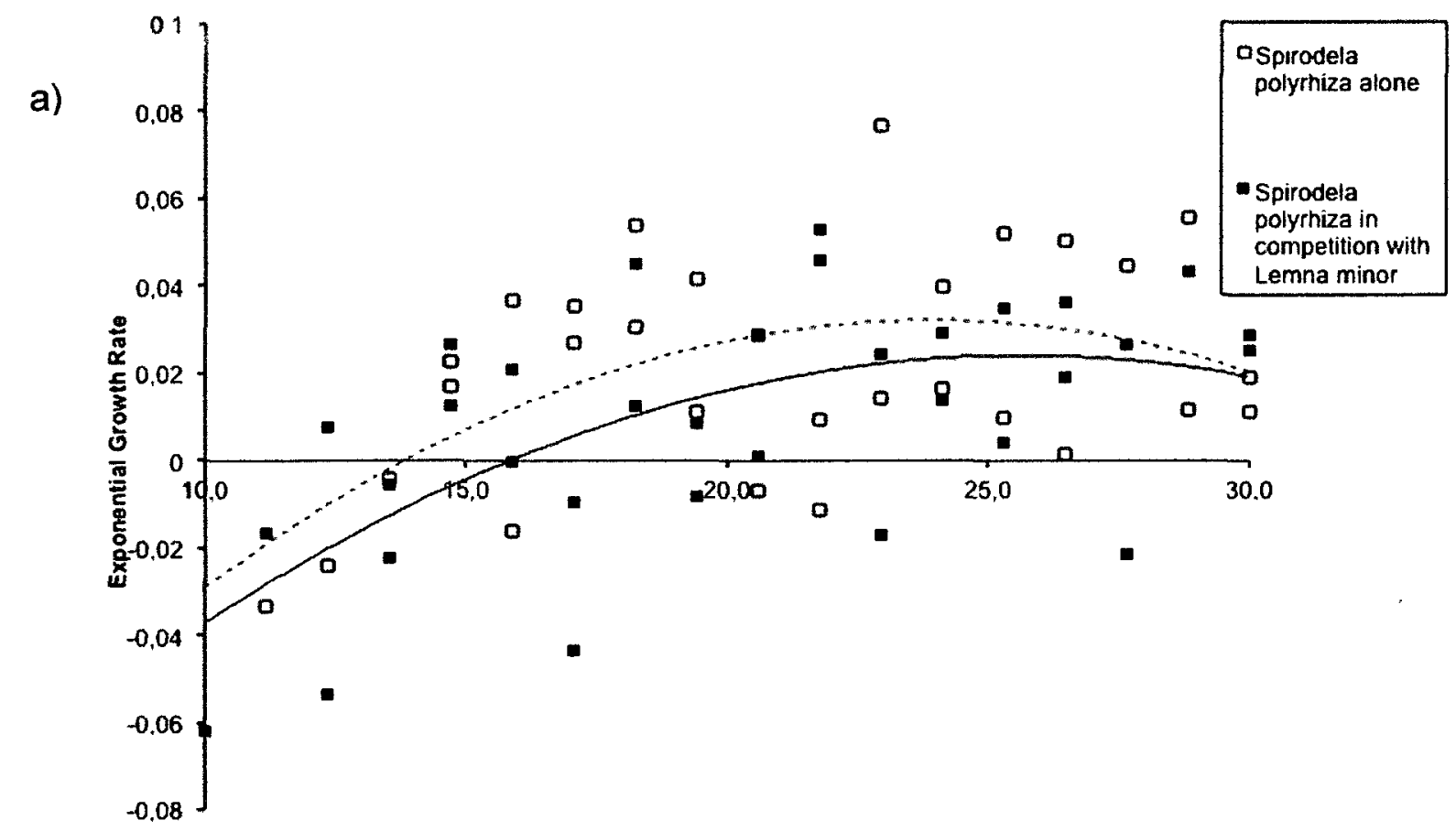

Temperature (C)

b)

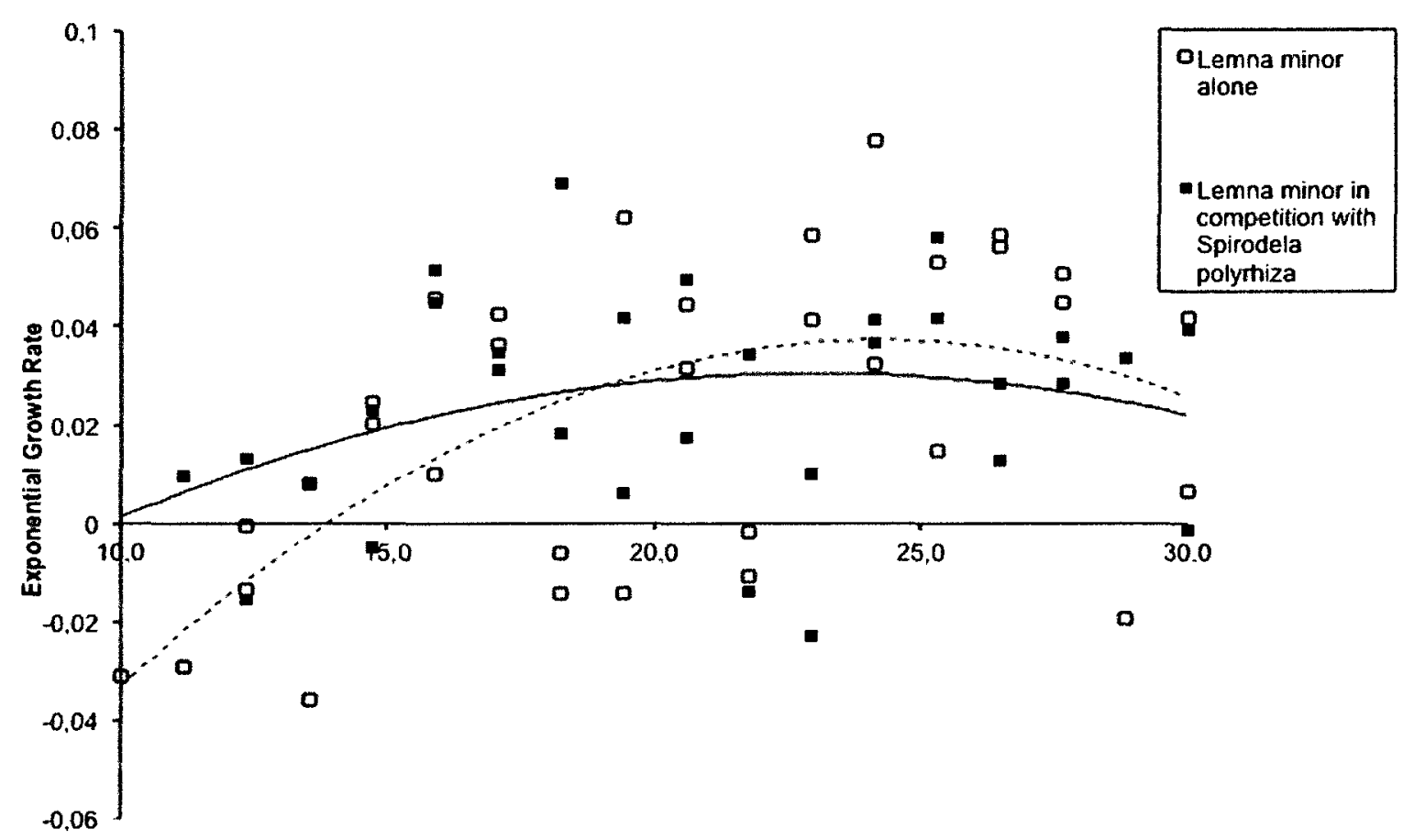

Temperature (C)

Figure 3: Exponential growth rate across a range of temperatures for (a) S. polyrhiza when grown in isolation and in a mixed community with $L$. minor and (b) for $L$. minor when grown in isolation and in a mixed community with $S$. polyrhiza. No significant difference was found between the datasets for $S$. polyrhiza when grown in isolation compared to in the mixed community and both could be described using a single second-order polynomial. For $L$. minor there was no significant difference between exponential growth rates of populations in isolation compared to those when in the mixed community. 
For the two-species community involving S. polyrhiza and L. trisulca, there was no significant difference (regression: $p=0.395$, d.f. $=56, F=1.011, R^{2}=0.1162$; ANCOVA: $p=0.228$, M.D. $=-0.002$, S.E. $=0.006$ ) between the curves of exponential growth rate vs. temperature of $L$. trisulca when grown in isolation compared to when in the mixed community with S. polyrhiza (Figure 4a). Additionally, S. polyrhiza did not have a statistically significant change (regression: $p=0.914$, d.f. $=61, F=0.1728, R^{2}=$ 0.3946; ANCOVA: $p=0.789$, M.D. $=0.036, S . E .=0.005)$ in exponential growth rate across a range of temperatures when grown in isolation and in the mixed community with L. trisulca (Figure 4b). 
a)

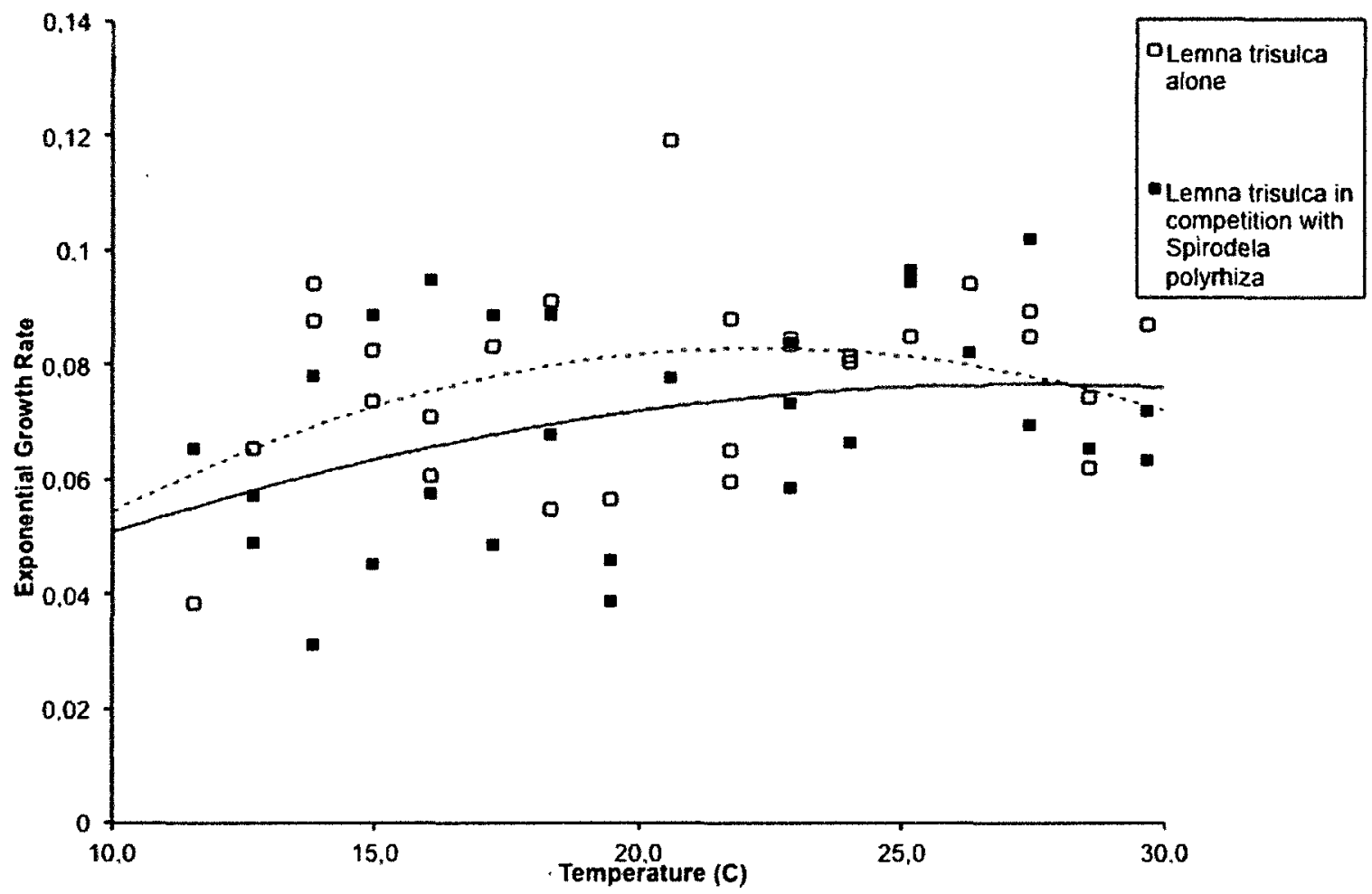

b)

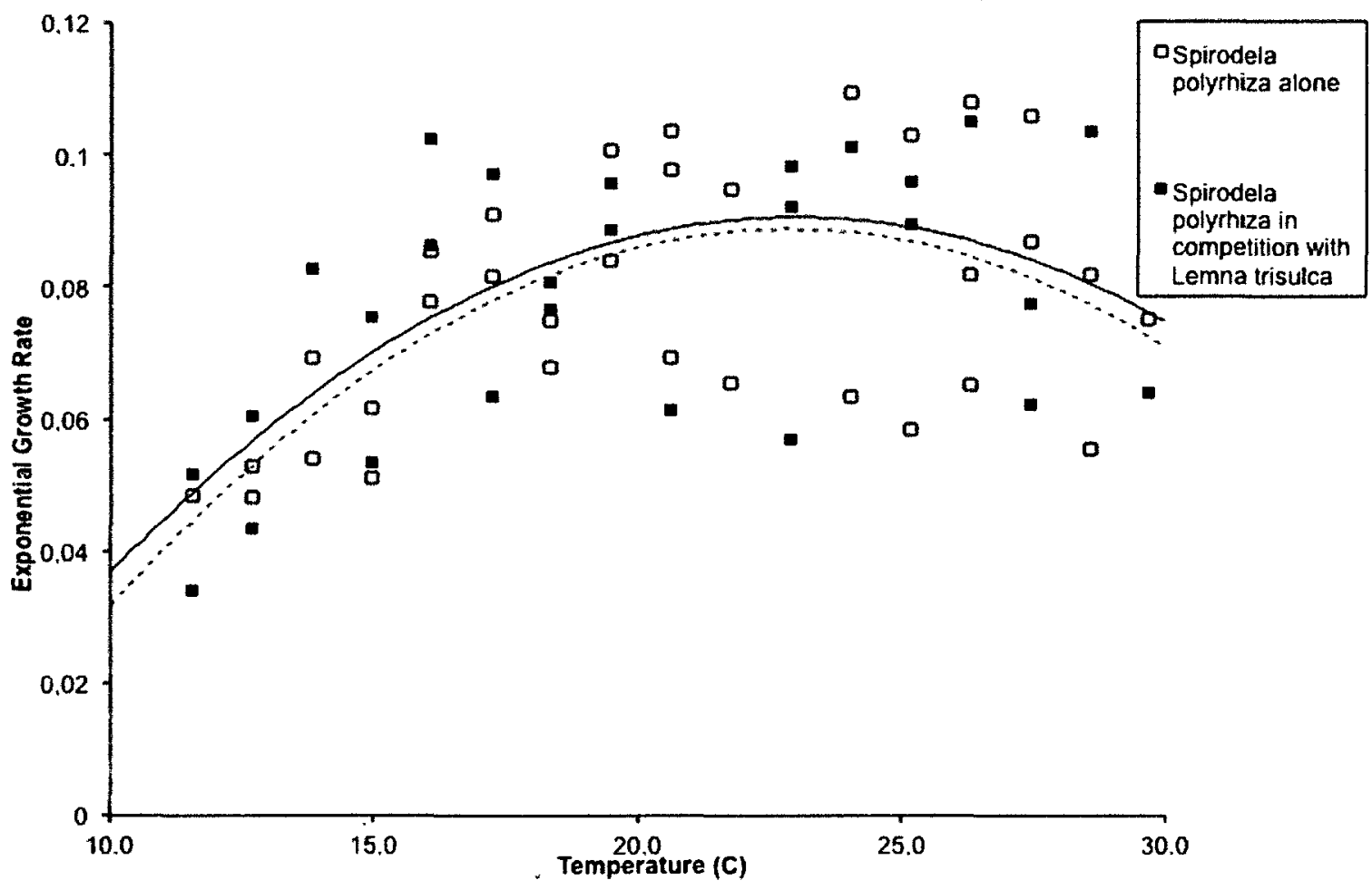

Figure 4: Exponential growth rate across a range of temperatures for (a) $L$. trisulca when grown in isolation and in a mixed community with $S$. polyrhiza and (b) for $S$. polyrhiza when grown in isolation and in a mixed community with $L$. trisulca. No significant difference between datasets was found for $L$. trisulca and both could be described using a single second-order polynomial. No significant difference was found between growth rates of $S$. polyrhiza when grown in isolation and in the mixed community. 
In the mixed two-species community composed of $L$. minor and $L$. trisulca, there was no statistically significant difference (regression: $p=0.587$, d.f. $=63, F=0.6482, R^{2}$ $=0.4718 ;$ ANCOVA: $p=0.477$, M.D. $=0.005$, S.E. $=0.007)$ between the exponential growth rate vs. temperature curves for $L$. minor when grown in isolation and in a mixed community with L. trisulca (Figure 5a). Similarly, for L. trisulca, there was no statistically significant difference (regression: $p=0.356$, d.f. $=41, F=1.113, R^{2}=0.2639$; ANCOVA: $p=0.052, M . D .=0.011$, S.E. $=0.006)$ between the exponential growth rate vs. temperature curve when grown in isolation and in a mixed community (Figure 5b). 
a)

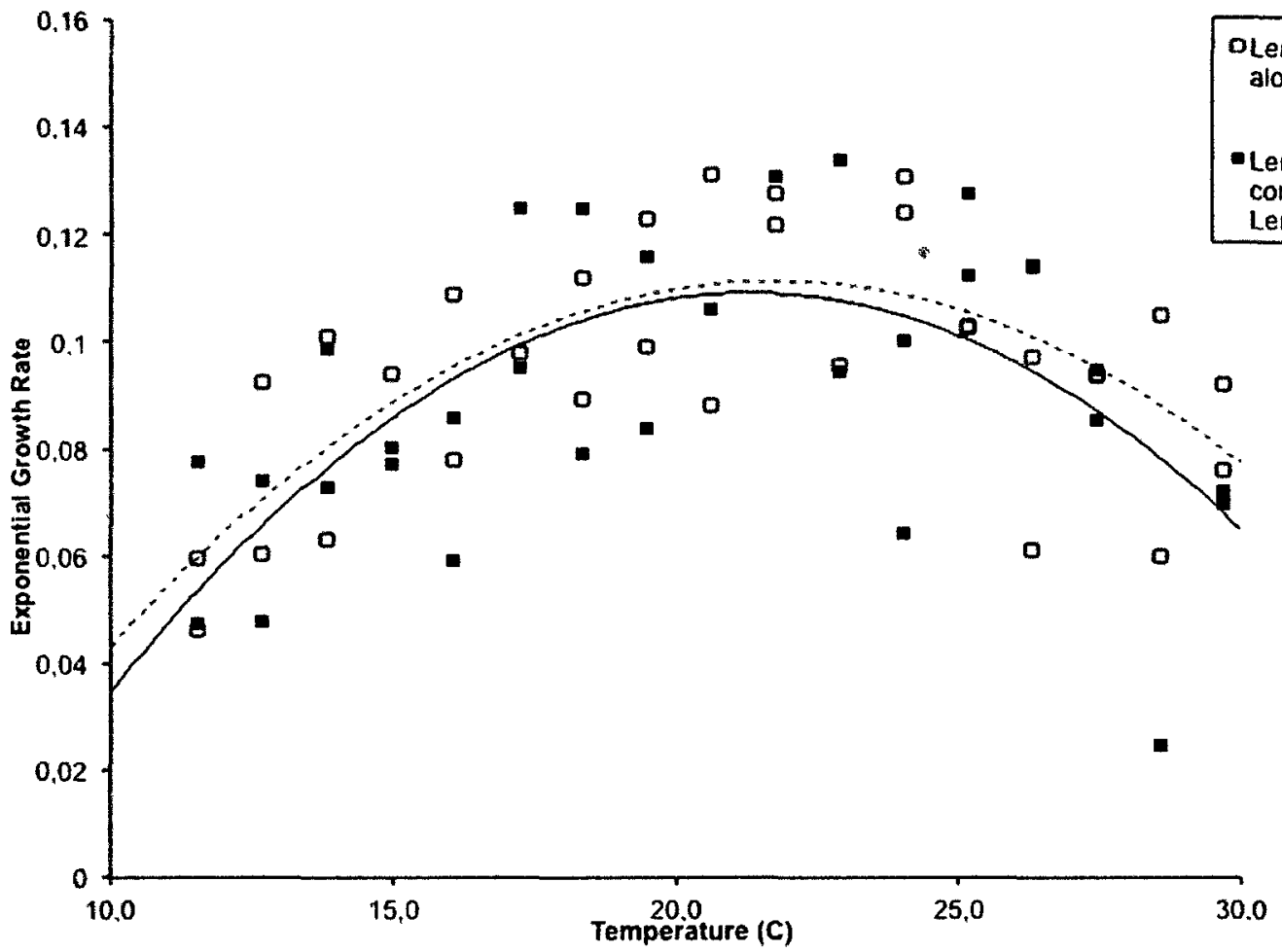

b)

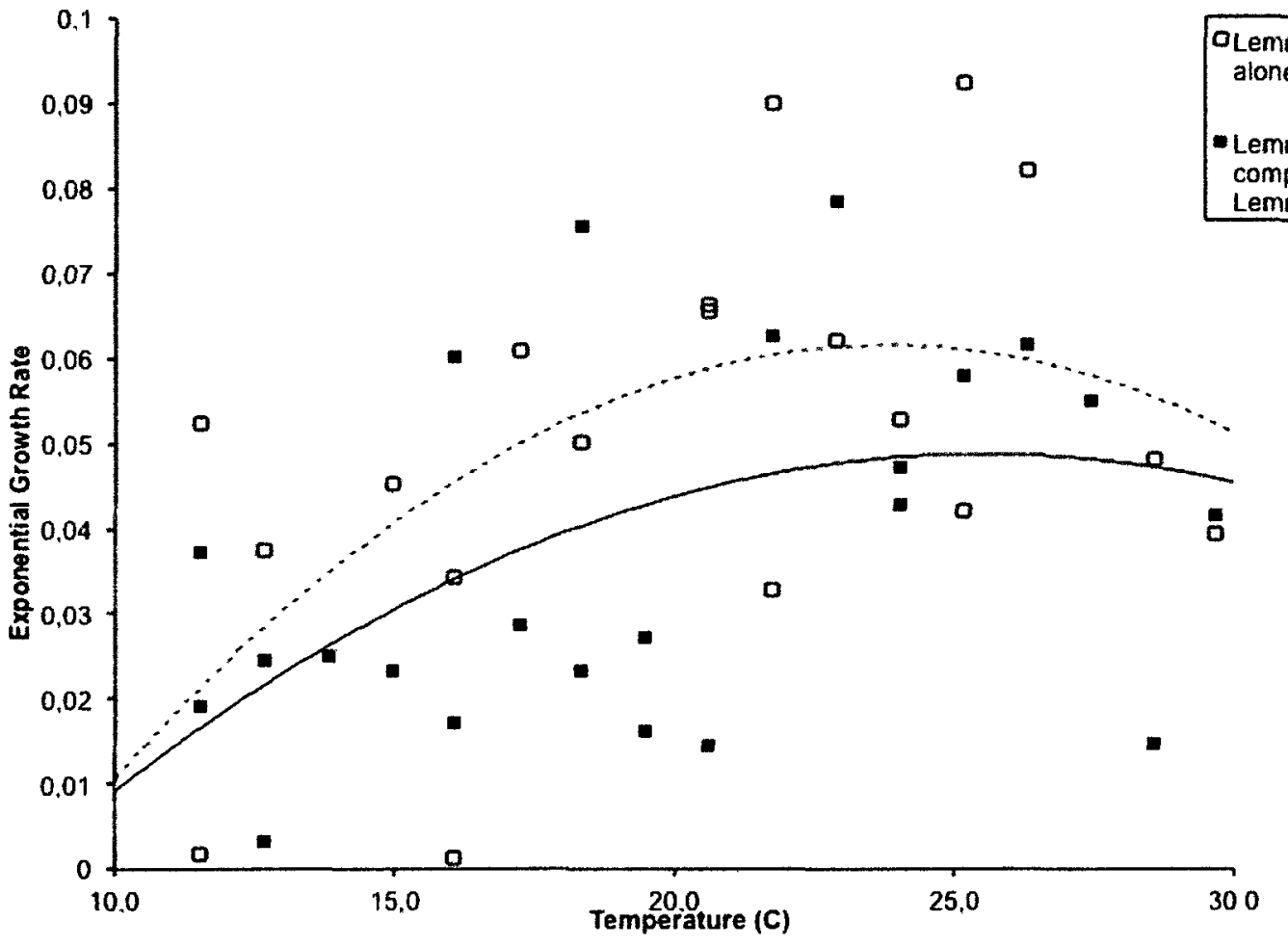

Figure 5: Exponential growth rate across a range of temperatures for $(a) L$. minor when grown in isolation and in a mixed community with $L$. trisulca and (b) for $L$. trisulca grown in isolation and in a mixed community with $L$. minor. No significant difference was found for the exponential growth rates of $L$. minor when grown in isolation and when in the mixed community. No significant difference was found between the exponential growth rates of isolated populations of $L$. trisulca compared to those of populations in the mixed community. 


\section{Temperature-dependent exponential growth rates of Lemnoidea in the three-species community compared to when in isolation or two- species communities}

For the three-species community, exponential growth rates across a temperature range for all three species were compared to those when grown in isolation and in a twospecies community.

\section{S. polyrhiza}

When S. polyrhiza was grown in the three species community, there was a significant difference in the exponential growth rate vs. temperature curve whereby $S$. polyrhiza had a significantly decreased exponential growth rate across the entire temperature range compared to when S. polyrhiza was grown in isolation (regression: $p<0.001$, d.f. $=67, F=8.286, R^{2}=0.5348 ;$ ANCOVA: $p=<0.001, M . D .=-0.028$, S.E. $=$ $0.06)$. This difference increased at warmer temperatures $\left(>24^{\circ} \mathrm{C}\right)$. In contrast to when $S$. polyrhiza was grown in the two-species community with $L$. trisulca, there was also a significant decrease in exponential growth rate across the entire temperature range (regression: $p<0.001$, d.f. $=79, F=64.09, R^{2}=0.1163 ;$ ANCOVA: $p<0.001$, M.D. $=-$ $0.061, \mathrm{~S} . \mathrm{E} .=0.005)$. This difference was greater at colder temperatures $\left(<24^{\circ} \mathrm{C}\right)$. The exponential growth rate of $S$. polyrhiza decreased at colder temperatures $\left(<20^{\circ} \mathrm{C}\right)$ when grown in the three-species community (regression: $p=0.049$, d.f. $=81, F=2.743, R^{2}=$ 0.4007 ; ANCOVA: $p=0.021$, M.D. $=0.007$, S.E. $=0.005)$ compared to when in the twospecies community with $L$. minor, however, at temperatures above $20^{\circ} \mathrm{C}$ there was an increase in its exponential growth rate (Figure 6). 


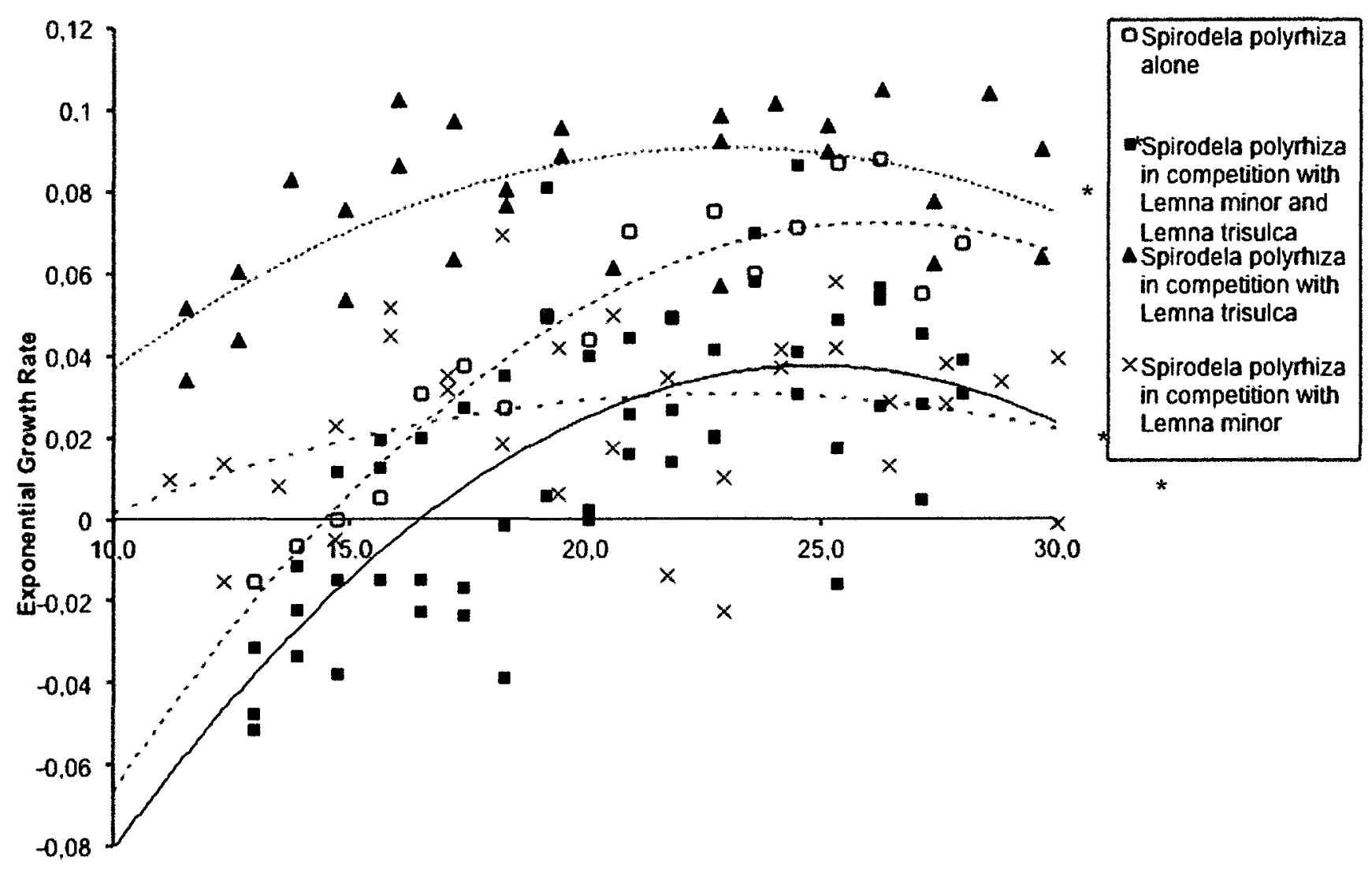

Temperature (C)

Figure 6: Exponential growth rate across a range of temperatures for $S$. polyrhiza when grown in a three-species community compared to when in two-species communities and in isolation. *There were significant differences between the exponential growth rates for $S$. polyrhiza in the three species community compared to those when in isolation and in two-species communities.

\section{L. minor}

There was a significant difference in the exponential growth rate vs. temperature curve for $L$. minor when grown in the three-species community and compared to when in isolation (regression: $p=0.001$, d.f. $=65, F=6.162, R^{2}=0.3282$; ANCOVA: $p<0.001$, M.D. $=-0.028, S . E .=0.008)$ and when in a two-species community with $L$. trisulca 
(regression: $p<0.001$, d.f. $=81, F=39.51, R^{2}=0.07748 ;$ ANCOVA: $p<0.001$, M.D. $=$ $0.051, S . E .=0.006)$. Although, there was a marginally nonsignificant difference for the non-linear regression $\left(p=0.0594\right.$, d.f. $=79, F=2.584, R^{2}=0.1976$ ) comparing the exponential growth rate vs. temperature curve for $L$. minor when grown in the threespecies community to that when in the two-species community with S. polyrhiza (Figure 7 ), this difference was marginally significant when analysed with ANCOVA ( $p=0.049$, M.D. $=0.012$, S.E. $=0.006)($ Figure 7$)$. In the three-species community, L. minor performed best at temperatures between $17^{\circ} \mathrm{C}-24^{\circ} \mathrm{C}$. Additionally, the decreased exponential growth rate of $L$. minor across the entire temperature range in the threespecies community was greatest at lower $\left(<17^{\circ} \mathrm{C}\right)$ and higher temperatures $\left(>24^{\circ} \mathrm{C}\right)$ (Figure 7). 


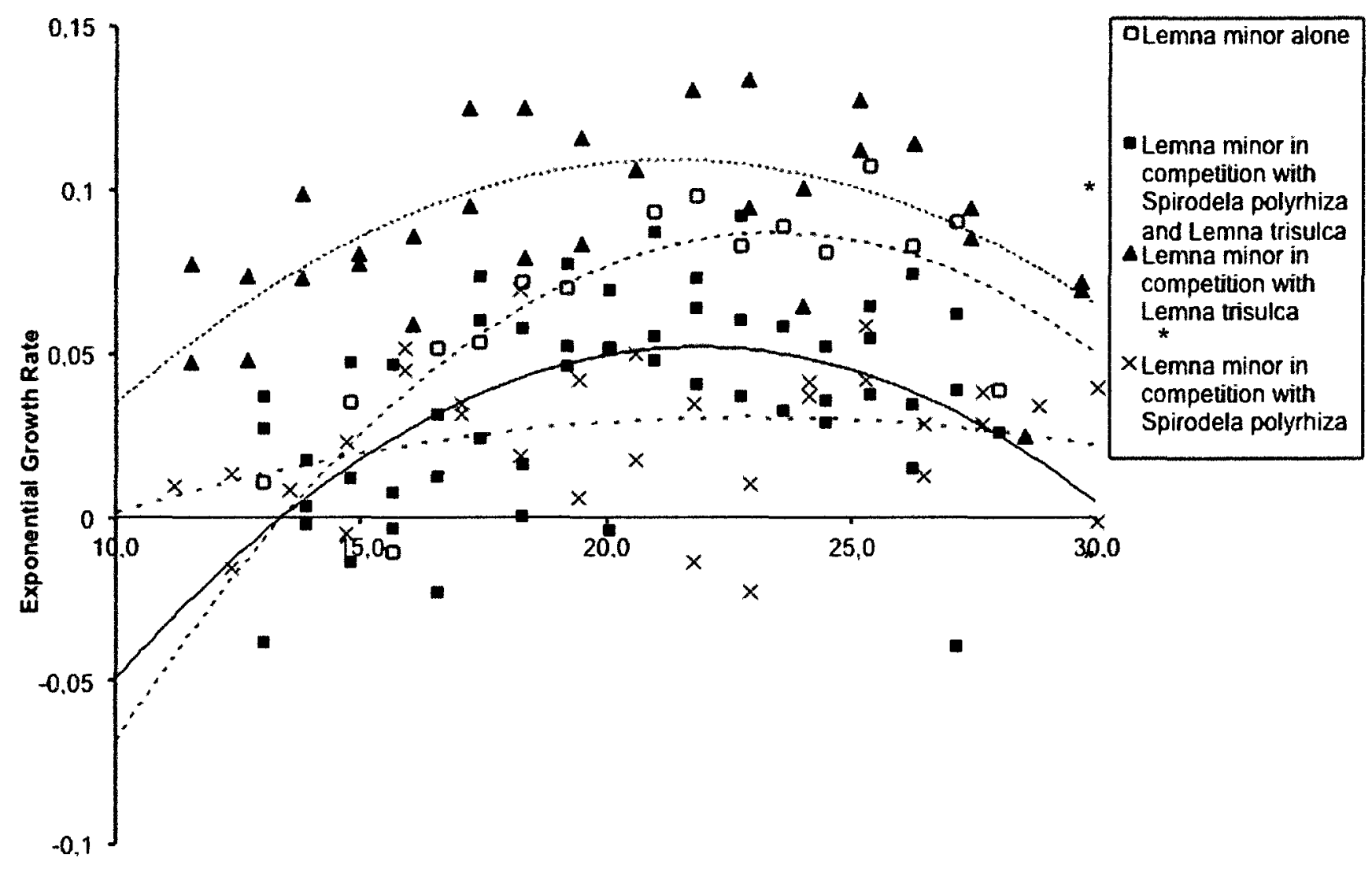

Temperature (C)

Figure 7: Exponential growth rate across a range of temperatures for $L$. minor when grown in a three-species community compared to when in two-species communities and in isolation. *There were significant differences between the exponential growth rates for $L$. minor in the three-species community when compared to those when in isolation and in a two-species community with $L$. trisulca. However mixed results were found when comparing $L$. minor in the three-species community to when it was in a two-species community with S. polyrhiza.

\section{L. trisulca}

For L. trisulca, there was a significant difference in the exponential growth rate vs. temperature curve when grown in the three-species community and compared to when in isolation (regression: $p=0.021$, d.f. $=60, F=3.494, R^{2}=0.1861 ;$ ANCOVA: $p=0.002$, M.D. $=-0.017$, S.E. $=0.005)$, and when in two-species communities with either $S$. polyrhiza (regression: $p<0.001$, d.f. $=73, F=71.34, R^{2}=0.09108$; ANCOVA $p<0.001$, 
M.D. $=-0.064$, S.E. $=0.004$ ) or L. minor (regression: $p<0.001$, d.f. $=68, F=18.47, R^{2}=$ $0.1020 ;$ ANCOVA $p<0.001$, M.D. $=-0.035$, S.E. $=0.005$ ). The overall exponential growth rate decreased for L. trisulca when in the three species community and compared to when grown in isolation and in two-species mixed communities. The exponential growth rate was positive across the entire temperature range for $L$. trișulca when grown in isolation and in two-species communities. However, although for L. trisulca when in the three-species community, exponential growth rates were positive at warmer temperatures, at temperatures less than $18^{\circ} \mathrm{C}$ the exponential growth rate was negative (Figure 8). 


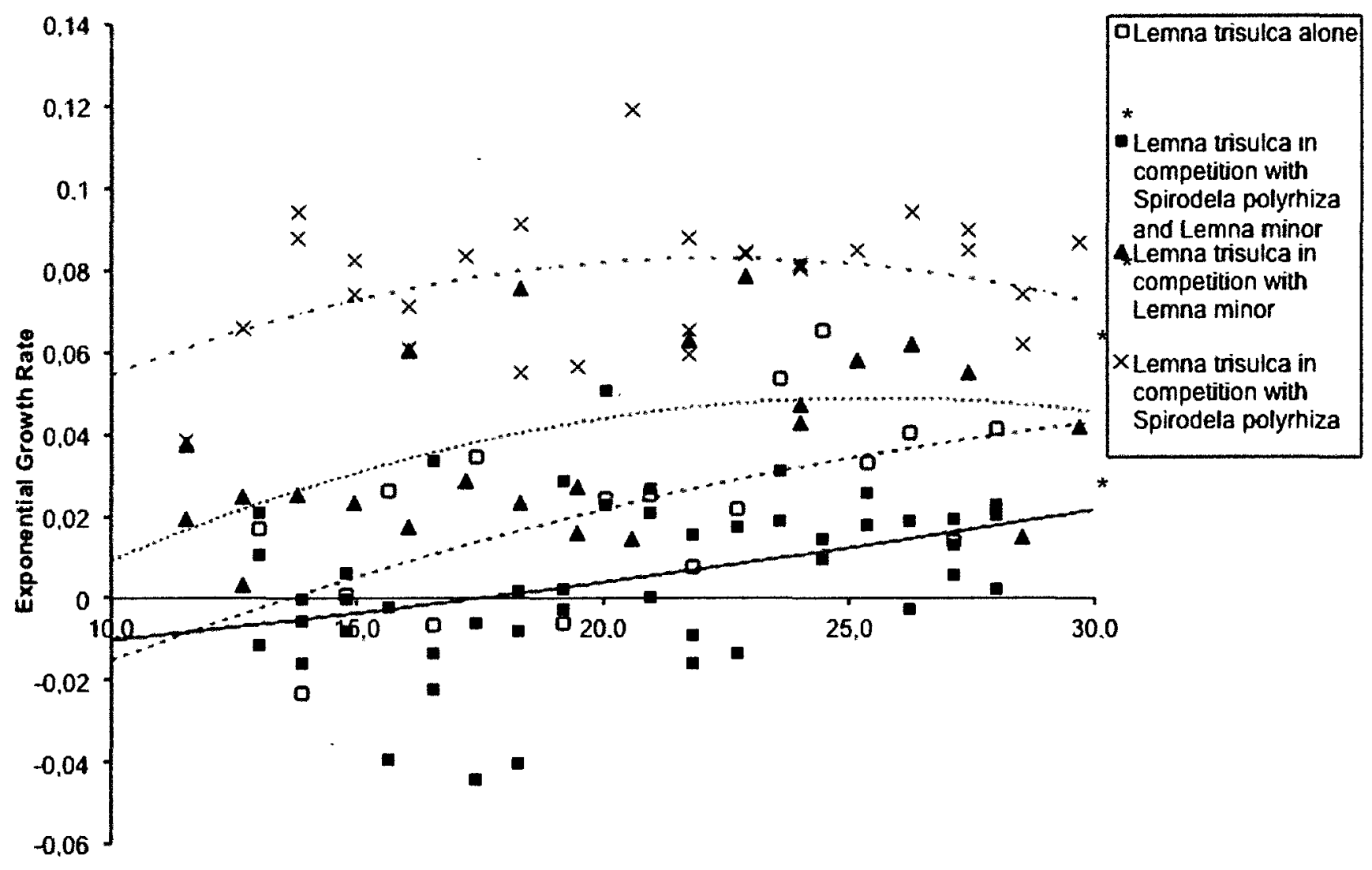

Temperature (C)

Figure 8: Exponential growth rate across a range of temperatures for $L$. trisulca when in a three-species community compared to when grown in two-species communities and in isolation. *There were significant differences between the exponential growth rates for $L$. trisulca in the three-species community compared to those when in isolation and in twospecies communities.

\section{Changes in average optimal growth temperature with increased community complexity}

Average optimal growth temperatures were calculated for each species from the first derivative of the exponential growth rate vs. temperature curve of populations grown 
in isolation, in two-species communities and in three-species communities (Figure 9). For S. polyrhiza there was an increase in the average optimal growth temperature when grown in two-species communities with either species compared to that when in the three-species community $\left(23.9^{\circ} \mathrm{C}\right.$ and $24.5^{\circ} \mathrm{C}$ respectively). There was no apparent difference in the average optimal growth temperature of $S$. polyrhiza when grown in isolation $\left(24.7^{\circ} \mathrm{C}\right)$ and compared to that when in either the two-species or three-species communities. For L. minor there were consistent decreases in average optimal growth temperature as community complexity increased from isolation $\left(23.9^{\circ} \mathrm{C}\right)$ to two-species communities with either other species $\left(22.3^{\circ} \mathrm{C}\right)$ to three-species communities $\left(21.4^{\circ} \mathrm{C}\right)$. In contrast, for $L$. trisulca there were no differences in average optimal growth temperature when comparing the multiple treatments whereby optimal growth temperature was $24.9^{\circ} \mathrm{C}$ when grown in isolation, $24.5^{\circ} \mathrm{C}$ when in a two-species community with either of the other species and $24.0^{\circ} \mathrm{C}$ when in a three species community. While these observations are suggestive, there was insufficient power to detect differences between these groups. An ANOVA performed on these observations demonstrated this lack of power and did not have a significant result $(p=0.7858, F=$ $0.4761, R^{2}=0.2092$, d.f. $\left.=14\right)$. 
a)

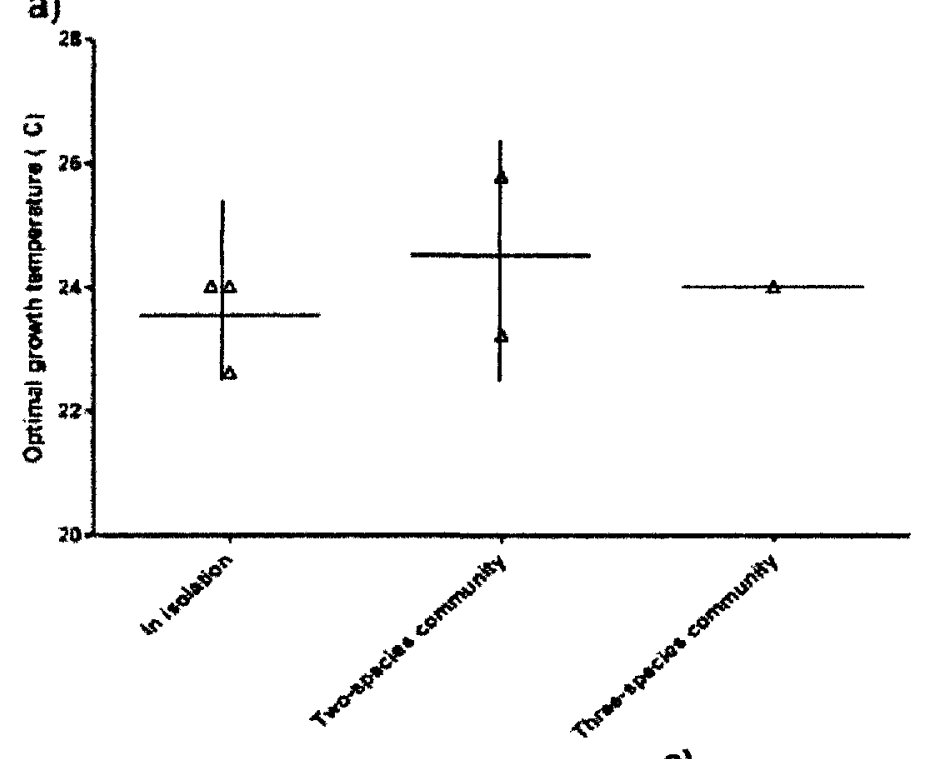

Treatment Type

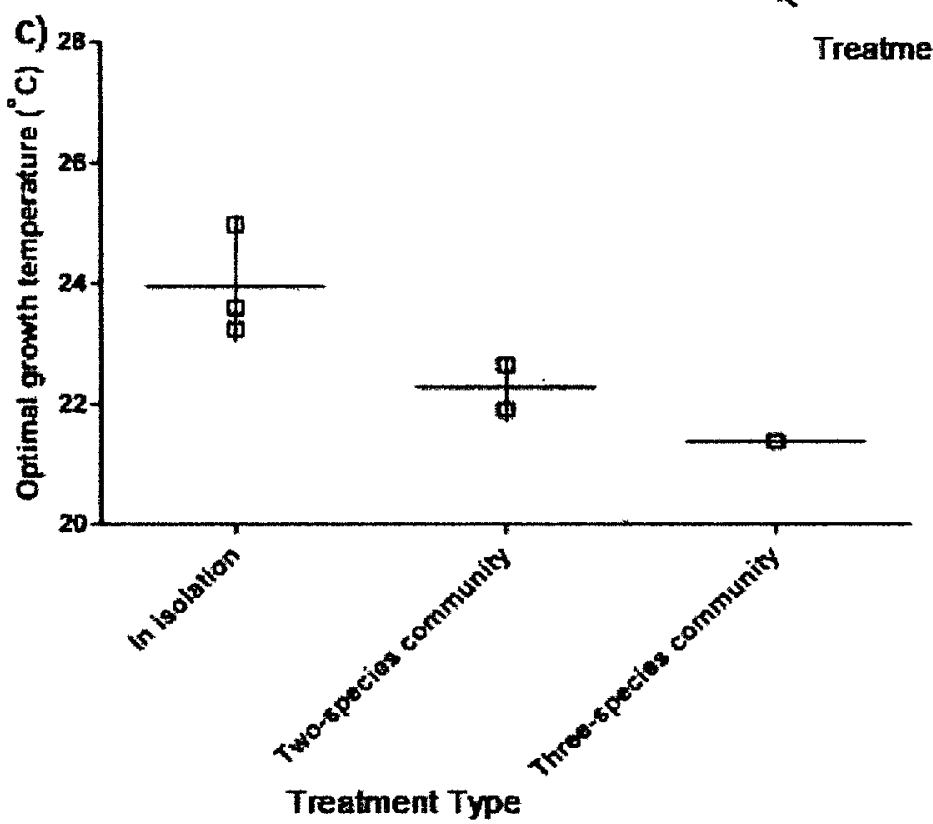

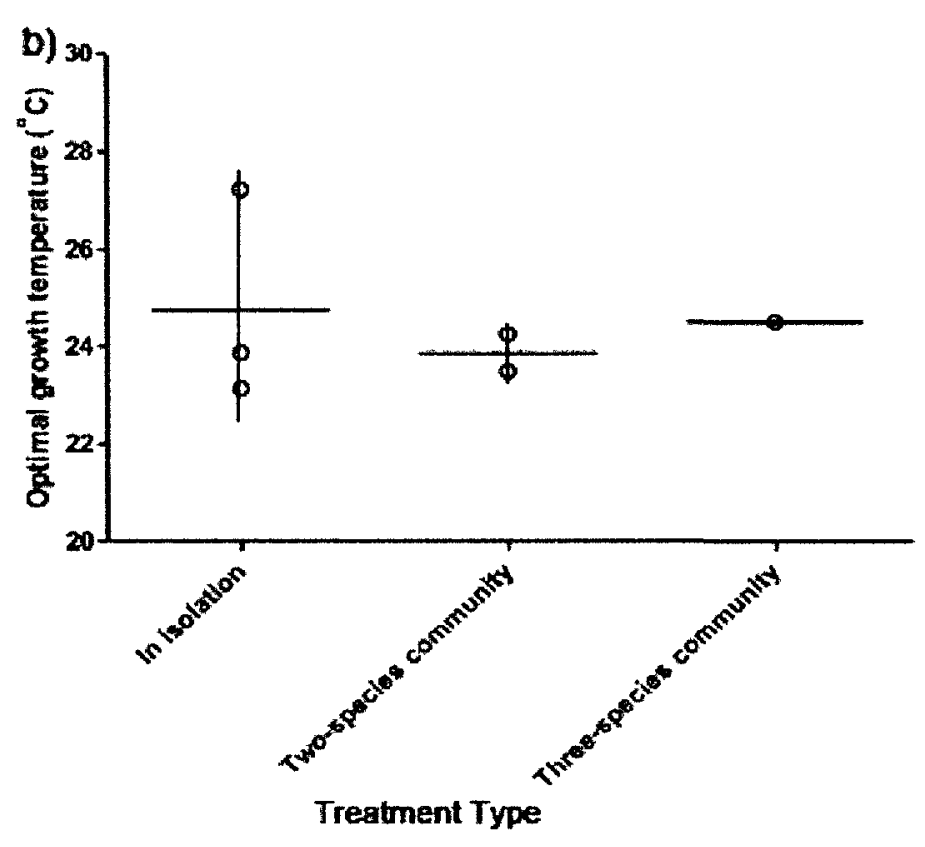

Treatment Type

Figure 9: Optimal growth temperature for each species when grown in isolation, in a two-species community and in a three-species community. Optimal growth temperatures were marked with a line representing the mean optimal growth, a) shows the optimal growth temperature for $L$. trisulca, b) shows the optimal growth temperature for $S$. polyrhiza, c) shows the optimal growth temperature for $L$. minor. Due to the lack of data points, statistical significance of these observations could not be determined. 


\section{Discussion}

The goal of this study was to determine how community complexity affects the temperature dependent fitness or competitive performance, as measured by exponential growth rate, of individual species. By defining exponential growth rate as the average exponential rate of change in biomass over the duration of the experiment, performance was determined for three competing native species of Lemnoideae: L. minor, S. polyrhiza and $L$. trisulca across a range of temperatures. These temperatures reflect variation found in the native habitat of these species (Environment Canada, 2011).

In this study, increased community complexity had an effect on the exponential growth rate of individual species in the community across a wide range of temperatures. In all six cases of the two-species communities, there was no statistically significant effect of community on the growth curves of each species when compared to those of species when grown in isolation. However an increase in complexity to a three-species community, resulted in statistically significant differences between growth curves of species in isolation or in two-species communities and in the mixed community. In addition to this, it was found that there were changes in average optimal growth temperature as community complexity varied, although these changes were species specific. For S. polyrhiza there was an apparent increase in average optimal growth temperature when in the three-species community compared to when in the two-species community although no difference was seen when comparing optimal growth temperature of isolated populations to that of when in either the two- or three-species communities. In contrast, as community complexity increased, optimal average 
temperatures for $L$. trisulca appeared to decrease. L. minor showed decreases in average optimum growth temperature with the highest temperature when grown in isolation and the lowest when in a three-species community.

Comparisons between individual species when grown in isolation showed that there are inherent inter-species differences in exponential growth rates. This is likely due to differences in life-history traits and the different niches they naturally inhabit.

Although for the two-species communities it was found that there were no significant differences in growth curves when compared to species in isolation, the apparent reduced growth rate of $L$. trisulca when in two-species communities suggest that $L$. trisulca may be more susceptible to interspecific competition than either $S$. polyrhiza or $L$. minor. The decreased growth rate for $L$. trisulca in more complex threespecies communities suggests that the cumulative effect of two competing species was greater than the effect of each individually. It has been found that in high nutrient systems, such as what was reproduced in this thermogradient model, light may become the limiting resource (Hauthier et al., 2009; Huisman and Weissing, 1995; Huston and DeAngelis, 1994; Tilman, 1985). As a result, species found at lower vertical positions experience greater interspecific stress from higher growing plants (Hauthier et al., 2009; Huisman and Weissing, 1995; Huston and DeAngelis, 1994; Tilman, 1985). L. trisulca is a subsurface dwelling species (Prasad, 2001) consequently it is possible that it was in a disadvantaged position when compared to S. polyrhiza and L. minor, which are surface dwelling plants (Pip, 1988). They may have been in an ideal position to block light to $L$. trisulca, and when present together in the three-species community, could have blocked 
even more light than either was able to do when in a two-species community due to the greater surface area covered by the two species together. These findings are in agreement with those of Mcllraith et al. (1989), which showed that in eutrophic areas $L$. minor dominated L. trisulca regardless of light levels; and with those of Keddy (1976), who determined the colonization capability of $L$. minor and $L$. trisulca and found that $L$. minor was a superior colonizer both in the laboratory setting and in water bodies across Southern Ontario.

For $L$. minor, there were significant differences between the exponential growth rate vs. temperature curve of the population grown in the three-species compared to the curves of the populations grown in isolation or in the community with L. trisulca. Additionally, there were suggestive similarities in exponential growth rate for the population in the three species community compared to that in the simpler community with S. polyrhiza. These findings suggest that for $L$. minor, competition was dependent on the presence of $S$. polyrhiza and the addition of $L$. trisulca did not have a significant effect on the competitive stress felt by $L$. minor. Both L. minor and S. polyrhiza are surface dwellers with similar nutrient requirements (Pip, 1988), consequently the proximity of the niche space between both species may be the underlying cause behind the interspecific stress exerted on L. minor by S. polyrhiza (Clatworthy and Harper, 1962; Pip, 1988; Reddy and DeBusk 1985). It has been suggested that closer niche proximity, especially among closely related species, results in increased interspecific competition (Cahill et al., 2008; Dayan and Simberloff , 2005). These findings support those of previous competition experiments such as by Woleck (1974) who, in comparative competitions involving S. polyrhiza, L. gibba, L. minor and Wolffia arrhiza, 
determined that $S$. polyrhiza was the superior competitor when compared to L. minor. Kaul and Bakaya (1976) found that, in competitions of S. polyrhiza, L. minor and L. trisulca, S. polyrhiza was again the stronger competitor over the two other species. Woleck (1984) further demonstrated that S. polyrhiza was a superior competitor over $L$. minor, even when multiple clonal lines with varying levels of competitive ability were used. Moreover, L. minor generally appears to be unaffected by the presence of $L$. trisulca in high-nutrient conditions likely because it is the stronger competitor (Keddy, 1976; Mcliraith et al., 1989) and its higher growth position allows it to overshadow and outcompete L. trisulca.

Since the differences between exponential growth rates across a range of temperatures of $L$. minor when in the three-species community and those when in the two-species community with S. polyrhiza were marginally non-significant when tested with a non-linear regression this suggests that it may be possible to determine how $L$. minor will respond in the three-species community given an understanding of how it is affected by S. polyrhiza. However, this difference was found to be marginally significant when tested with ANCOVA and as a result, further work is required to determine the significance of this relationship.

For S. polyrhiza there was a difference between exponential growth rates when in a three-species community and when in isolation, and in a two-species community with L. minor or L. trisulca. This suggests that increased community complexity had a significant effect on the exponential growth rate over a temperature range of $S$. polyrhiza. Whereas isolated populations did not significantly differ in exponential growth 
rate from populations in two-species communities, the decrease in exponential growth rate in the three species community suggests that, similar to L. trisulca, there was a cumulative effect of both competing species that was greater than the impact of each individually. This cumulative effect has been previously reported in other models such as the model described by Bella (1971) which explored pure and mixed stands of Pseudotsuga menziesii, Pinus bandsianam P. resinosa and Populus temuloids to determine the influence that neighbouring trees had on any given individual and found that increased numbers of competitors and effects from individual size resulted in overall decreased growth rates due to competition. Furthermore, Facelli (1994) found that multiple effects of leaf litter, herb competition and insect herbivory were all implicated in Ailanthus altissima seedling establishment and growth. Vinebrooke et al. (2004) found that single stressors in anthropogenically acidified and circumneutral lakes resulted in tolerant species compensating for more sensitive competitors but that these compensations were greatly reduced as the number of stressor increased.

In this study, as community complexity increased, there were several changes in average optimal growth temperature. The increased optimal temperature of S. polyrhiza with increased community complexity could result in increased performance of $S$. polyrhiza at higher temperatures in more complex communities. Increased temperature as a result of climatic changes could therefore allow S. polyrhiza to outcompete cold biased species and dominate regions in which it would otherwise have been unable to outcompete species (Thuiller et al., 2005). In contrast, L. minor shifted to a colder optimal temperature as community complexity increased. It is interesting that these two species could demonstrate differing coping mechanisms in response to competition. 
This idea could be further explored in an evolutionary system to determine if these changes in niche space would result in an adaptive response. The shift in the optimal temperatures of $S$. polyrhiza and $L$. minor could result from competitive repulsion between the two wherein the niche space of each species is changing. Similar shifts in niche-space as a result of competition have been previously observed for multiple systems such as changes in breeding period for harpactoid copepods in intertidal habitats (Hockin and Ollason, 1981), variations in the gall form amongst subspecies of tephritid flies (McArthur et al., 1979), the wintering distribution and abundance patterns of multiple species of birds (Bock et al., 1977; Bock et al., 1978) and the food resource partitioning of six species of sponge-eating dorid nudibranchs (Bloom, 1981). It is thought to be a process that reduces niche overlap between close competitors (Darlington, 1972).

There was no statistically significant effect of community complexity on the average optimal growth temperature of $L$. trisulca. However, there is an apparent decrease in optimal temperature with increasing community complexity. Similarly to $L$. trisulca, L. minor decreased in average optimal growth temperature with each increasing level of community complexity. This could put $L$. minor at a disadvantage should temperatures increase as a result of climatic changes as it has been suggested that cold-biased species are more vulnerable to climatic changes (Thuiller et al., 2005). Should invasive species enter an area previously dominated by $L$. minor, the increased community complexity could result in a colder average optimal growth temperature of $L$. minor. This lowered average optimal growth temperature could cause a significant decrease in productivity and fitness as ambient temperatures move further away from 
the optimum (Hill and Magnuson, 1990). If this were to happen, L. minor would likely be outcompeted by invasive species, possibly to the point of local extinction (Mooney and Cleland, 2001).

While the three-week time frame of each experimental run may have been insufficient to allow for complete competitive exclusion, the observations of this study lead to several predictions of what the final outcome of each competition would have been. It is likely that in this experiment, even if each experimental run had been allowed to continue until the community reached a steady state, $L$. trisulca would never dominate a community at any temperature as multiple studies have shown it is not competitive enough. However, it will probably always still be found in small quantities in the high light, high nutrient environments (Dickinson and Miller, 1998; Gopal and Goel, 1993; Krull, 1969; Mcllraith et al., 1989). In warm temperatures above $23^{\circ} \mathrm{C}$, exponential growth râtes for $S$. polyrhiza were greâter than those of $L$. minor when in the threespecies community. At these temperatures, one could predict that $S$. polyrhiza would dominate, and competitively exclude L. minor which would in turn exclude S. polyrhiza at lower temperatures where $L$. minor had a greater exponential growth rate. These predictions based on our findings are similar to what has been observed in waterways where areas were dominated either by $L$. minor or S. polyrhiza and within these populations, small numbers of $L$. trisulca were often found (Hiliman, 1961; Hotchkiss, 1972; Jacobs, 1947; Kandeler, 1989; Keddy, 1976).

The results from the three-species community, both in terms of growth curve location and shape as well as optimal temperature, were unexpected given the lack of 
statistically significant differences between isolated populations and two-species communities. Additionally, there were statistically significant differences between the exponential growth rates of two-species communities and those of three-species communities. This suggests that the addition of even a single species changes the growth curves of each species involved. Furthermore, it has been shown in single temperature systems that the addition of species to a community can change interspecific interactions from competitive to faculative (Levine, 1976). Davis et al. (1998a; 1998b) reported similar results in studies of multiple Drosophila species where the temperature response curves of individual species changed depending on whether the populations were segregated by species or were mixed. These findings also raise questions as to the validity of models and predictions that are based on observations of isolated species or of pairwise, direct interactions. Gilman et al. (2010) reported that a lack of inclusion of species interaction effects is the underlying cause behind a lack of accurate predictions regarding ćlimate change. Despite recent studies showing that these interactions are affected by climate change in a wide range of terrestrial systems, including those amongst plants and animals (Tyliankis et al., 2008), community interactions are often left out of models (Sharma et al., 2007) and this absence can result in false predictions (Araujo and Luoto, 2007; Heikkinen et al., 2007; Memmott et al., 2007). Indeed, it has been found that the inclusion of interactions in climate change models can improve predictions and accuracy (Guisan and Thuiller, 2005; Heikkinen et al., 2007; Pearson and Dawson, 2003). The findings presented here provide empirical evidence of how a closed system may react to climatic changes, an essential starting point in understanding how more complex, open systems may respond (Gilman et al., 2010). 
The main limitation in exploring the effect of community complexity in this study was that there. were only three species used, thereby representing a very simple community. Given that it was found that the addition of a single species when going from a two- to a three-species community resulted in statistically significant changes in the exponential growth vs. temperature curves for all species involved, it would be worthwhile exploring whether further increases in community complexity would have a similar effect. By using a more diverse selection of species, it would be possible to determine the effect of increasingly complex communities on the exponential growth rate of individual species across a range of temperatures and to determine if there is a critical level or threshold of complexity, after which the addition of further species would cease to have a significant effect.

The 21 day duration of each experimental run likely resulted in species still being within the exponential increase còmponent of their logistic growth curvès (Driever et al., 2005; Underwood and Baker, 1991). If so, inter- and intra-specific interactions could have been reduced, communities would not have reached equilibrium and competitive exclusion may not have occurred. By providing more time for communities to reach an equilibrium or steady-state composition, outcomes such as competitive exclusion could be studied.

It could prove useful to have a dynamic temperature regime in which the temperature of the thermogradient apparatus would be changed following the development and stabilisation of communities. This would simulate predicted future 
temperatures for natural communities (Hughes et al., 2003; Karl and Trenberth, 2003; Thomas et al., 2004) as a result of global climatic change, and examine how a previously stable community would respond to these disturbances.

The static nature of the thermogradient apparatus also ignored diurnal changes in temperature. As the model organisms of this study were floating aquatic plants, there is a consistent and predictable cycling of temperatures in natural habitats throughout the day-night cycle (Kaplan et al., 2003). It has been found that these cycles are especially pronounced in the upper layers of shallow water bodies where these species are found (Jacobs et al., 1998).

Furthermore, the permanent long-term temperature changes that can occur as a result of global climatic changes, seasonal changes in light, nutrients and temperature were not reproduced. Depending on geographic location, seasonal changes can be quite significant. In the Ottawa area where samples of the model organism were taken, average daily temperatures fluctuate from $5.7^{\circ} \mathrm{C}$ to $20.9^{\circ} \mathrm{C}$ throughout the growing season (Environment Canada, 2011). Additionally, in Ottawa day lengths vary from approximately 9 hours to 15 hours (University of Nebraska-Lincoln, 2010). There are seasonal fluctuations in nutrient load in natural water bodies (Carlson, 1977) that were not reproduced in this experiment. While a lack of seasonal variations may not have had a significant effect on this experiment due to the relatively short experimental time frame of 21 days, these factors should not be ignored in studies that examine community development over a longer period of time. 
Future work should focus on confirming and expanding upon the finding of this study through experiments with larger sample sizes over a longer period of time. Additionally, future work should also include a dynamic component in temperature treatments. Using a model system that can incorporate diurnal and seasonal variations in temperature, light and nutrient loading could provide valuable insight into how these factors will affect changes in community composition and the response of individual species to temperature changes. Moreover, they will assist in the transition from models of closed systems to models of open systems.

Testing the effect of community complexity through the use of model systems made up of greater plant species diversity, including species from aquatic, marine and terrestrial systems should be explored. This would confirm whether the findings of this study are limited to Lemnoideae or extend to other aquatic plants, and whether they are valid across a wide range of species. It may also be useful to examine the effect of community complexity when sessile and non-sessile species are intermixed in either micro- or macrocosm models to determine if and how factors such as movement, dispersal and migration can influence community interactions. The addition of herbivory may also have a significant effect on the outcome of competition and on final community composition. It was found in arctic species, that increased temperature resulted in altered community composition in the absence of herbivory but not when herbivores were present (Post and Pedersen, 2008).

Evolutionary rescue, novel mutations or the increase in frequency of previously rare alleles can allow populations to survive in otherwise fatal environments (Bell and 
Gonzalez, 2009). The inclusion of sexually reproductive species, especially those with a high rate of mutation or genetic diversity, in future experiments could demonstrate the role that evolutionary rescue and adaptation could have in mitigating the effect that changes in community complexity and temperature have on individual species

Overall, these findings have shown that while simpler communities did not affect the exponential growth vs. temperature curves for individual species, increased community complexity resulted in significant changes in the location and shape of these curves. This suggests that models and predictions based solely upon observations of species that are in isolation may not accurately represent the effects of temperature change. The change in average optimal growth temperature for several species that were observed as community complexity varied, suggests that some species may be more susceptible to climatic changes as a result of interspecific competition and community complexity. This study provides important insights regarding the importance of community complexity and competitive interactions between species at different temperatures. It provides information concerning the possible ecological and evolutionary effects of climate change on aquatic plant communities and is a starting point for further studies that will focus on the impacts of climate change and community dynamics. 


\section{References}

Agami, M., and Reddy, K.R., 1989. Inter-relationships between Salvinia rotundifolia and Spirodela polyrhiza at various interaction stages. Journal of Aquatic Plant Management 27: 96-102.

Appenroth, K.J., Teller, S., and Horn, M., 1996. Photophysiology of turion formation and germination in Spirodela polyrhiza. Biologia Plantarum 38(1): 95-106.

Appenroth, K.J., 2002. Clonal differences in the formation of turions are independent of the specific turion-inducing signal in Spirodela polyrhiza (Great duckweed). Plant Biology 4: 688-693.

Appenroth, K.J., and Ziegler, P., 2008. Light-induced degredation of storage starch in turions of Spirodela polyrhiza depends on nitrate. Plant, Cell and Environment 31: 1460 1469.

Araujo, M.B., and Luoto, A., 2007. The importance of biotic interactions for modeling species distributions under climate change. Global Ecology and Biogeography 16(6):743-753.

Arber, A., 1920. Water plants. A study of aquatic angiosperms. Cambridge University Press. Cambridge, UK.

Barnes, P.W., Jordan, P.W., Gold, W.G., Flint, S.D, and Caldwell, M.M., 1988.

Competition, morphology and canopy structure in wheat (Triticum aestivum L.) and wild oat (Avena fatua L.) exposed to enhanced ultraviolet-B radiation. Functional Ecology 2: 319-330.

Bassi, R., and Sharma, S.S., 1993. Changes in proline content accompanying the uptake of zinc and copper by Lemna minor. Annals of Botany 72(2): 151-154.

Beerling, D.J., 1993. The impoact of temperature on the northern distribution limits of the introduced species Fallopia japonica and Impatiens glandulifera in north-west Europe. Journal of Biogeography 20: 45-53.

Bell, G., and Collins, S., 2008. Adaptation, extinction and global change. Evolutionary Applications 1(b): 3-16.

Bella, I.E., 1971. A new competition model for individual trees. Forest Science 17(3): 364-372.

Bell, G., and Gonzalez, A., 2009. Evolutionary rescue can prevent extinction following environmental change. Ecology Letters 12(9): 942-948.

Bella, I.E., 1971. A new competition model for individual trees. Forest Science 17(3):364-372. 
Ben-Tal, Y., and Cleland, C.F., 1981. Uptake and metabolism of $\left[{ }^{14} \mathrm{C}\right]$ Salicylic acid in Lemna gibba G3 ${ }^{1,2}$. Plant Physiology 70: 291-296.

Bhalla, P.R., Pieterse, A.H., and Sabharwa, P.S., 1973. Some aspects of flowering, gibbosity and turion formation in Lemnaceae. Acta Botanica Neerlandica 22(4): 433-445.

Bloom, S.A., 1981. Specialization and noncomeptitive resource partitioning among sponge-eating dorid nudibranchs. Oecologia 49(3): 305-315.

Bock, C.E., Bock J.H., and Lepthien, L.W., 1977. Abundance patterns of some bird species wintering on the Great Plains of the USA. Journal of Biogeography 4: 101-110

Bock, C.E., Mitton, J.R., and Lepthien, L.W., 1978. Winter biogeography of North American fingillidae (aves): a numerical analysis. Systematic Biology 27(4): 411-420.

Bonte, D., Hovestadt, T., and Poethke, H.-J., 2009. Sex-specific dispersal and evolutionary rescue in metapopulations infected by male killing endosymbionts. $B M C$ Evolutionary Biology 9:16-25.

Bradshaw, W.E., and Holzapfel, C.M., 2006. Evolutionary response to rapid climate change. Science 312: 1477-1478.

Bradshaw, W.E., and Holzapfel, C.M., 2008. Genetic response to rapic climate change: it's seasonal timing that matters. Molecular Ecology 17: 157-166.

Brubaker, L.B., and McLachlan, J.S., 1996. Landscape diversity and vegetation response to long-term climate change in the eastern Olympic Peninsula, Pacific Northwest, USA. In Global Change and Terrestrial Ecosystems. Walker, B., and Steffan, W., (eds) Cambridge University Press, Cambridge.

Cabrera, L.I., Salazar, G.A., Chase, M.W, Mayo, S.J., Bogner, J., and Davila, P., 2008. Phylogenetic relationships of aroids and duckweeds (Araceae) inferred from codings and noncoding plasmoid DNA. American Journal of Botany 95(9): 1153-1165.

Cahill JF Jr, Kembel SW, Lamb EG, and Keddy PA, 2008. Does phylogenetic relatedness influence the strength of competition among vascular plants? Perspectives in Plant Ecology, Evolution and Systematics 10:41-50.

Callaway, R.M., and Pennings, S.C., 2000. Facilitation may buffer competitive effects: indirect and diffuse interactions among salt marsh plants. American Naturalist 156(4): 416-424.

Chesson, P., 1994. Multispecies competition in variable environments. Theoretical population biology 45(3): 227-276.

Clark, H.L., 1979. In Godfrey, R.K., and Wooten, J.W., (eds) Aquatic and wetland plants of southeastern United States. The University of Georgia Press. Athens USA 
Clatworthy, J.N., and Harper, J.L., 1972. The comparative biology of closely related species living in the same area. V. Inter and intraspecific interference within cultures of Lemna sp. and Salvinia natans. Journal of Experimental Botany 13: 307-324.

Cleland, C.F., and Tanaka, O., 1982. Influence of plant growth substances and salicylic acid on flowering and growth in the Lemnaceae. Aquatic Botany 13: 3-20

Connel, J.H., 1961. The influence of competition and other factors on the distribution of the barnacle Chthamalus stellatus. Ecology 40: 49-78.

Connolly, J., and Wayne, P., 2005. Assessing determinants of community biomass composition in two-species plant competition studies. Oecologia 142: 450-457.

Connolly, J., Wayne, P.M., and Murray, R., (1990) Time course of plant-plant interactions in experimental mixtures of annuals: density, frequency, and nutrient effects. Oecologia 82: 513-526.

Coulston, J.W., and Riitters, K.H., 2005. Preserving biodiversity under current and future climates: a case study. Global Ecology and Biogeography 14: 31-38.

Dalén, L., Nyström, V., Valdiosera, C., Germonpré, M., Sablin, M., Turner, E., Angerbjörn, A., Arsuga, J.L., and Götherström, A., 2007. Ancient DNA reveals lack of postglacial habitat tracking in the arctic fox. Proceedings of the National Academy of Sciences of the United States of America 104(16): 6726-6729.

Darlington PJ, 1972. Competition, competitive repulsion, and coexistence. Proceedings of the National Academy of Science of the United States of America 69(11): 3151-3155.

Davis, M.B., 1981. Quaternary history and the stability of forest communities. In Forest Succession, Concepts and Application. West, D.C., Shugart, H.H., and Botkin, D.B., (eds). Springer Verlag, New York.

Davis, M.B., 1986. Climate instability, time lags and community disequilibria. In Community Ecology. Diamond, J., and Case, T.J., (eds) Harper and Row, New York.

Davis, A.J., Jenkinson, L.S., Lawton, J.H., Shorrocks, B., and Wood, S., 1998a. Making mistakes when predicting shifts in species range in response to global warming. Nature 391: 783-786

Davis, A.J., Lawton, J.H., Shorrocks, B., and Jenkinson, L.S., 1998b. Individualistic species responses invalidate simple physiological models of community dynamics under global environmental change.. Journal of Animal Ecology 67: 600-612.

Dayan, T., and Simberloff, D., 2005. Ecological and community-wide character displacement: the next generation. Ecology Letters 8: 875-894.

Den Hartog C., and van der Plas, F., 1970. A synopsis of the Lemnaceae. Blumea 18: 355-368. 
Dickinson, M.B., and Miller, T.E., 1998. Competition among small, free-floating aquatic plants. The American Midland Naturalist 140(1): 55-67.

Driever, S.M., van Nes, E.G.H., and Roijackers, R.M.M., 2005. Growth limitation of Lemna minor due to high plant density. Aquatic Botany 81(3): 245-251.

Environment Canada 2011. Canadian Climate Normals 1971-2000 for Ottawa MacDonald-Cartier International Airport. Accessed 15 May 2011 at $\mathrm{http}$ ://www.climate.weatheroffice.gc.ca/climate_normals/results_e.html?stnID=4337\&aut ofwd $=1$

Facelli, J.M., 1994. Multiple indirect effects of plant litter affect the establishment of woody seedlings in old fields. Ecology 75(6): 1727-1735.

Fernald, M.L., 1950. Gray's Manual of Botany. American Book Company New York 385387.

Fox, J.W., Morin, P.J., 2001. Effects of intra- and interspecific interactions on species responses to environmental change. Journal of Animal Ecology 70(1): 80-90.

Froeschke, G., Harf, R., Sommer, S., and Matthee, S., 2010. Effects of precipitation on parasite burden along a natural climatic gradient in southern Africa - implications for possible shifts in infestation patterns due to global changes. OIKOS 119(6): 1029-1039.

Gifford, R.M., Barrett, D.J., Lutze, F.L., and Samarakoon, A.B., 1996. Agriculture and global change: scaling direct carbon dioxide impacts and feedbacks through time. In Walker, B., and Steffen, W., (eds) Global Change and Terrestrial Ecosystems.

Cambridge University Press, Cambridge.

Gilman, S.E., Urban, M.C., Tewksbury, J., Gilchrist, G.W., and Holt, R.D., 2010. A framework for community interactions under climate change. Trends in Ecology and Evolution 25(6):325-331.

Glandon, R.P., and McNabb, C.D., 1978. The uptake of boron by Lemna minor. Aquatic Botany 4: 53-64.

Gopal, B., and Goel, U., 1993. Comeptition and allelopathy in aquatic plant communities. The Botanical Review 59(3): 155-210.

Graham, C., Ferrier, S., Huettman, F., Moritz, C., Peterson, A., 2004. New developments in museum-based informatics and applications in biodiversity analysis. Trends in Ecology and Evolution 19: 497-503.

Grieneisen, M.L., and Zhang, M., 2011. The current status of climate change research. Nature Climate Change 1: 72-73. 
Griffiths, R.A., Sewell, D., McCrea, R.S., 2010. Dynamics of a declining amphibian metapopulation: survival, dispersal and the impact of climate. Biological Conservation 143(2): 485-491.

Guisan, A., and Thuiller, W., 2005. Predicting species distribution: offering more than simple habitat models. Ecology Letters 8(9): 993-1009.

Guisan, A., and Zimmermann, N.E., 2000. Predictive habitat distribution models in ecology. Ecological Modelling 135: 147-186.

Hanksi, I., Thomas, C.D., 1994. Metapopulations dynamics and conservation: a spatially explicit model applied to butterflies. Biology of Conservation. 68: 167-180.

Harris, A.H., 1993. Wisconsinian pre-pleniglacial biotic change in southeastern New Mexico. Quarternary Research 40: 127-133.

Hauthier, Y., Niklaus, P.A., and Hector, A., 2009. Competition for light causes plant biodiversity loss after eutrophication. Science 324: 636-638.

Heikkinen, R.K., Luoto, M., Virkkala, R., Pearson, R.G., and Körber, J.K., 2007. Biotic interactions improve prediction of boreal bird distributions at macro-scales. Global Ecology and Biogeography 16(6):754-763.

Hill, D.K., and Magnuson, J.J., 1990. Potential effects of global climate warming on the growth and prey consumption of Great Lakes fish. Transactions of the American Fisheries Society 119(2): 265-275.

Hillman, W.S., 1959(a). Experimental control of flowering in Lemna I. General Methods. Photoperiodism in L. Pepusilla 6746. American Journal of Botany 46: 466-473

Hillman, W.S., 1959(b). Experimental control of flowering in Lemna II. Some effects of medium composition, chelating agents and high temperatures on flowering in $\mathrm{L}$. perpusilla 6746. American Journal of Botany 46: 489-496

Hillman, W.S., 1959(c). Experimental control of flowering in Lemna III. A relationship between medium compositions and the opposite photoperiodic responses of $\mathrm{L}$. perpusilla 6746 and L. gibba G3.

Hillman, W.S. 1961. The Lemnaceae or duckweeds: a review of the descriptive and experimental literature. The Botanical Review 48(5) 221-287.

Hockin, D.C., and Ollason, J.G., 1981. The colonization of artificially isolated volumes of intertidal estuarine sand by harpacticoid copepods. Journal of Experimental marine Biology and Ecology. 53: 9-29.

Hotchkiss, N., 1972. Common Marsh, underwater and floating-leaved plants of the United States and Canada. Dover Publications, New York, USA; London, UK; Don Mills, Can. 
Houghton, J.T., et al. (eds) in Climate Change 2001: The Science of Climate Change. Cambrige University Press, New York.

Hughes, T.P., Baird, A.H., Bellwood, D.R., Card, M., Connolly, S.R., Folke, C., Grosberg, R., Hoegh-Guldberg, O., Jackson, J.B.C., Kleypas, J., Lough, J.M., Marshall, P., Nyström, M., Palumbi, S.R., Pandolfi, J.M., Rosen, B., and Roughgarden, J., 2003. Climate change, human impacts, and the resilience of coral reefs. Science 301(5635): 929-933

Huisman, J., and Weissing, F.J., 1995. Competition for nutrients and light in a mixed water column: a theoretical analysis. The American Naturalist 146(4):536-564.

Huston, M.A., and DeAngelis, D.L., 1994. Competition and coexistence: the effects of resource transport and supply rates. The American Naturalist 144(6):954-977.

Ibanez, I., Clark, J.S., Dietze, M.C., Feeley, K., Hersh, M., LaDeau, S., McBride, A., Welch, N.E., and Wolosin, M.S., 2006. Predicting biodiversity change: outside the climate envelope, beyond the species-area curve. Ecology 87(8):1896-1906.

Jacobs A.F.G., Heusinkveld B.G., Nieveen J.P., 1998. Temperature behaviour of a shallow water body during a summer period. Theoretical and Applied Climatology 59 (12):121-127.

Jacobs, D.L., 1947. An ecological life-history of Spirodela polyrhiza (greater duckweed) with emphasis on the turion phase. Ecological Monographs 17(4): 437-469.

Jeffree, E.P., and Jeffree, C.E., 1996. Redistribution of the potential geographic ranges of Mistletoe and Colorado Beetle in Europe in response to the temperature component of climate change. Functional Ecology 10: 562-577.

Jiguet, F., Gadot, A.-S., Julliard, R., Newson, S.E., Couvet, D., 2007. Climate envelope, life history traits and the resilience of birds facing global change. Climate Change Biology 13: 1672-1684.

Jump, A.S., and Penuelas, J., 2005. Running to stand still: adaptation and the response of plants to rapid climate change. Ecology Letters 8(9): 1010-1020.

Kandeler, R. 1989 Lemnaceae. CRC Handbook of Flowering Volume 3. ed. A.H. Halevy. CRC Press, Boca Raton, FI. pp 251-278.

Kaplan, D.M., Lergier, J.L., Navarrete, S., Guines, R., and Castilla, J.C., 2003. Large diurnal temperature fluctuations in the nearshore water column. Estuarine Coastal and Shelf Science 57: 385-398.

Karl, T.R., and Trenberth, K.E., 2003. Modern global climate change. Science 302(5651): 1719-1723. 
Kaul , V., and Bakaya, U., 1976. The noxious floating lemnid-Salvinia aquatic weed complex in Kashmir. Pages 188-192, in C.K. Varshney and J. Rzoska (eds) Aquatic weeds in south east Asia. W. Junk, The Hague.

Keddy, P.A., 1976. Lakes as islands: the distributional ecology of two aquatic plants, Lemna minor L. and Lemna trisulca L. Ecology 57(2):353-359.

Kingsolver, J.G., and Gomulkiewicz, R., 2003. Environmental variation and selection on performance curves. Integrative and Comparative Biology 43(3): 470-477.

Krajncic, B., and Nemec, J., 2003. Mechanisms of EDDHA effects on the promotion of floral induction in the long-day plant Lemna minor (L.). Journal of Plant Physiology 160(2): 143-151.

Krull, J.N., 1969. Factors affecting plant die-offs in shallow water areas. American Midland Naturalist 69:293-295.

Lake, J.A., and Wade, N., 2009. Plant-pathogen interactions and elevated CO2: morphological changes in favour of pathogens. Journal of Experimental Botany 60 : 3123-3131.

Landolt, E., 1986. The family Lemnaceae - a monographic study 1. Veröff. Geobot. Inst. ETH, Stiftung Rübel, Zürich.

Landolt, E., Kandeler, R., 1987. The family of Lemnaceae - a monographic study 2. Biosystematic inversitgatons in the family of duckweeds (Lemnaceae). Veröff. Geobot. Inst. ETH, Stiftung Rübel, Zürich.

Lankau, R.A., Nuzzo, V., Spyreas, G., and Davis, A.S., 2009. Evolutionary limits ameliorate the negative impact of an invasive plant. Proceedings of the National Academy of Science of the United States of America 106(36): 15362-15367.

Lemon, G.D., Posluszny, U., and Husband, B.C., 2001. Potential and realized rates of vegetative reproduction in Spirodela polyrhiza, Lemna minor, and Wolffia borealis. Aquatic Botany 70: 79-87.

Levine, S.H., 1976. Comeptitive interactions in ecosystems. American Naturalist 110:903-910.

Li, Y.P., Acharya, K., Chen, D., and Stone, M., Modeling water ages and thermal structure of Lake Mead under changing water levels. Lake and Reservoir Management 26(4): 258-272.

Loarie, S.R., Duffy, P.B., Hamilton, H., Asner, G.P., Field, C.B., and Ackerly, D.D., The velocity of climate change. Nature 462: 1052-1057.

Lotka, A.J., 1922. Contribution to the energetics of evolution. Proceedings of the National Academy of Sciences of the United States of America 8(6): 147-151. 
McArthur, E.D., Tiernan, C.F., and Welch, B.L., 1979. Subspecies specificity of gall forms on Chysothamnus nauseousus. Western North American Naturalist 39(1): 81-88.

Mcllraith, A.L., Robinson G.G.C., and Shay, J.M., 1989. A field study of competetion and interaction between Lemna minor and Lemna trisulca. Canadian Journal of Botany 67(10): 2904-2911.

Memmott, J., Craze, P.G., Waser, N.M., and Price, M.V., 2007. Global warming and the disruption of plant-pollinator interactions. Ecology Letters 10(8):710-717.

Milchunas, D.G., Sala, O.E., and Lauenroth, W.K., 1988. A generalized model of the effects of grazing by large herbivores on grassland community structure. The American Naturalist 132(1): 87-106.

Miznera, F., and Meszéna, G., 2003. Spatial niche packing, character displacement and adaptive speciation along and environmental gradient. Evolutionary Ecology Research 5: 1-20.

Mooney, H.A., and Cleland, E.E., 2001. The evolutionary impact of invasive species. Proceedings of the National academy of Science of the United States of America. 98(10): 5446-5451.

Morrison, J.I., and Morecraft, M.D., 2006. Plant growth and climate change. WileyBlackwell, New York.

Motulski, H.J., 1999. Analyzing data with Graphpad Prism. Graphpad Software Inc.

National Climatic Data Center, 2011. NCDC: Global Surface Temeprature Anomalies. Accesed 08 June 2011 from http://www.ncdc.noaa.gov/cmb-faq/anomalies.php

Njambuya, J., Stiers, I., and Triest, L., 2011. Competition between Lemna minuta and Lemna minor at different nutrient concentrations. Auqatic Botany 94: 158-164.

Ohlberger, J., Edeline, E., Vollestad, L.A., Stenseth, N.C., and Claessen, D., 2011. Termperature-driven regime shifts in the dynamics of size-structured populations. The American Naturalist 177(2): 211-223.

Ornes, W.H., Sajwan, K.S., Dosskey, M.G., and Adriano, D.C., 1991. Bioaccumulation of selenium by floating aquatic plants. Water, Air and Soil Pollution 57-58: 53-57.

Parmesan, C., 2006. Ecological and evolutionary responses to recent climate change. Annual Review of Ecological and Evolutionary Systematics 37: 637-669.

Pearson, R.G., and Dawson, T.P., 2003. Predicting the impacts of climate change on the distribution of species: are bioclimate envelope models useful? Global Ecology and Biogeography 12:361-371. 
Pineda, E., and Lobo, J.M., 2009. Assessing the accuracy of species distribution models to predict amphibian species richness patterns. Journal of Animal Ecology 78(1): 182190.

Pip, E., 1988. Niche congruency of aquatic macrophytes in central North America with respect to 5 water chemistry parameters. Hydrobiologia 162: 173-182.

Porter, J., 1995 in Insects in a Changing Environment. Harrington, R., and Stork, N.E., (eds) Academic Press, London. pp. 93-123

Post E, Pedersen C, 2008. Opposing plant community responses to warming with and without herbivores. Proceedings of the Nationals Academy of Sciences of the United States of America 105(34): 12353-12358.

Pounds, J.A., Bustamante, M.R., Coloma, L.A., Conseugra, J.A., Fogden, M.P.L., Foster, P.N., La Marca, E., Masters, K.L., Merino-Viteri, A., Peuschendorf, R., Ron, S.R., Sanchez-Azofeifa, G.A., Still, C.J., and Young, B.E., 2006. Widespread amphibian extinctions from epidemic disease driven by global warming. Nature 439: 161-167.

Prasad MNV, Malec P, Waloszek A, Bojko M, Strzalka K, 2001. Physiological reponses of Lemna trisulca L. (duckweed) to cadmium and copper bioaccumulation. Plant Science 161: 881-889.

Rahel, F.J., and Olden, J.D., 2008. Assessing the effects of climate change on aquatic invasive species. Conservation Biology 22(3): 521-533.

Reddy, K.R., and DeBusk, W.F., 1985. Growth characteristics of aquatic macrophytes cultured in nutrient enriched water: II. Azolla, duckweed and Salvinia. Economic Botany 39(2): 200-205.

Rogers, D.J., and Randolph, S.E., 1993. Distribution of tsetse and ticks in Africa: past, present and future. Parasitology Today 9: 266-271.

Root, T.L., Price, J.T., Hall, K.R., Schneider, S.H., Rozenzweig, C., and Pounds, J.A., 2003. Footprints of global warming on wild plants and animals. Nature 421: 57-60.

Rubidge, E.M., Monahan, W.B., Parra, J.L., Cameron, S.E., and Brashares, J.S., 2011. The role of climate, habitat, and species co-occurrence as drivers of change in small mammal distributions over the past century. Global Change Biology 17(2): 696-708.

Schneider, S.H., and Root, T.I., in Status and Trends of the Nation's Biological Resources Part 1. Mac, M.J., Opler, P.A., Haecker, P.N., and Doran, P.D., (eds). US Geographical Survey, Reston Virginia. pp 89-116.

Schröer, M., Wittmann, A.C., Grüner, N., Steeger, H.U., Bock, C., Paul, R., and Pörtner, H.O., 2009. Oxygen limited tolerance and performance in the lugwork Arenicola marina: a latitudinal comparison. Journal of Experimental Marine Biology and Ecology 372: 2230. 
Scott, D., and Poynter, M., 1991. Upper temperature limits for trout in New Zealand and climate change. Hydrobiology 222: 147-151.

Sharma, S., Jackson, D.A., Minns, C.K., and Shuter, B.J., 2007. Will northern fish populations be in hot water because of climate change? Global Change Biology 13: 2052-2064.

Shi, J., Abid, A.D., Kennedy, I.M., Hristova, K.R., and Silk, W.K., 2011. To duckweeds (Landoltia punctata), nanoparticulate copper oxide is more inhibitory than the soluble copper in the bulk solution. Environmental Pollution 5: 1277-1282.

Simons, A.M., 2011. Modes of response to environmental change and the elusive empirical evidence for bet hedging. Proceedings of the Royal Society B 278: 1601-1609.

Simons, A.M., and Wagner, I., 2005. The characterization of complex continuous norms of reaction. Oikos 116: 986-994.

Song, G., Hou, W., Wang, Q., Wang, J., Jin, X., 2006. Effect of low temperature on eutrophicated waterbody restoration by Spriodela polyrhiza. Bioresource Technology 97 : 1865-1869.

Sutherst, R.W., Maywald, G.E., and Skarrat, D.B., 1995 in Insects in a Changing Environment. Harrington, R., and Stork, N.E. (eds) Academic Press, London.

Szabo S, Scheffer M, Roijackers R, Waluto B, Braun M, Nagy PT, Borics G, Zambrano L 2010. Strong growth limitation of a floating plant (Lemna gibba) by the submerged macrophyte (Elodea nottallii) under laboratory conditions. Freshwater Biology 55:681690.

Takimoto, A., Kaihara, S., and Yokoyama, M., 1994. Stress-induced factors involved in flower formation in Lemna. Physiologia Plantarum 92(4): 624-628.

Theo, J., Elzenga, M., Prins, H.B.A., and Stefels, J., 2000. The role of extracellular carbonic anhydrase activity in inorganic carbon utilization of Phaeocystis globosa (Prymnesiophyceae): a comparison with other marine algae using the isotopic disequilibrium technique. Limnology and Oceanography 45(2): 372-380.

Thomas, C.D., Cameron, A., Green, R.E., Bakkenes, M., Beaumont, L.J., Collingham, Y.C., Erasmus, B.F.N., de Siqueira, M.F., Grainger, A., Hannah, L., Hughes, L., Huntley, B., van Jaasveld, A.S., Midgley, G.F., Miles, L., Ortega-Huerta, M.A., Townsend Peterson, A., Phillips, O.L., and Williams, S.E., 2004. Extinction risk from climate change. Nature 427: $145-148$

Thuiller, W., Lavorel, S., and Araujo, M.B., 2005. Niche properties and geographical extent as predictors of species sensitivity to climate change. Global Ecology and Biogeography 14:347-357. 
Tilman, D., 1977. Resource competition between planktonic algae: an experimental and theoretical approach. Ecology 58(2): 338-348.

Tilman, D., 1985. The resource-ratio hypothesis of plant succession. The American Naturalist 125(6):827-852.

Tilman, D., 1994. Competition and biodiversity in spatially structured habitats. Ecology 75(1): 2-16.

Tingley, M.W., Monahan, W.B., Beissinger, S.R., and Moritz, C., 2009. Birds track their Grinnellian niche through a century of climate change. Proceedings of the National Academy of Sciences of the United States of America 106: 19637-19643.

Tyliankis, J.M., Didham, R.K., Bascompte, J., and Wardle, D.A., 2008. Global change and species interactin in terrestrial ecosystems. Ecology Letters 11:1351-1363.

Underwood, G.J.C., and Baker, J.H., 1991. The effect of various aquatic bacteria on the growth and senescence of duckweed (Lemna minor). Journal of Applied Bacteriology 70:192-196.

University of Nebraska-Lincoln 2010. Daylight hours explorer. Accessed 15 May 2011 at http://astro.unl.edu/classaction/animations/coordsmotion/daylighthoursexplorer.html

Valentine, J.W., and Jablonski, D., 1993. Fossil communities: composition variation at many time scales. In R.E. Ricklefs and D. Schluter (eds) Species Diversity in Ecological Communities. University of Chiacago Press, Chicago. pp 341-349.

Van der Heide, T., Roijackers, R.M.M., Peeters, E.T.H.M., Van Nes, E.H., 2006a. Experiemnts with duckweed-moth systems suggest that global warming may reduce rather than promote herbivory. Freshwater Biology 51(1): 110-116.

Van der Heide, T., Roijackers, R.M.M., van Nes, E.H., Peeters, E.T.H.M., 2006b. A simple equation describing the temperature dependent growth of free-floating macrophytes. Aquatic Botany 84: 171-175.

Vasseur, L., L.W. Aarssen, and T. Bennett. 1983. Allozymic variation in local apomictic populaitons of Lemna minor (Lemnaceae). American Journal of Botany 80(8): 974-979.

Villalpando, S.N., Williams, R.S., and Norby, R.J., 2009. Elevated air temperature alters an old-field insect community in a multifactor climate change experiment. Global Change Biology 15: 930-942.

Vinebrooke, R.D., Cottingham, K.L., Norberg, J., Scheffer, M., Dodson, S.I., Meberly, S.C., Sommer, U., 2004. Impacts of multiple stressors on biodiversity and ecosystem functioning: the role of species co-tolerance. Oikos 104: 451-457. 
Vonlanthen, P., Roy, D., Hudson, A.G., Largriader, C.R., Bittner, D., and Seehausen, O., 2009. Divergence along a steep ecological gradient in lake whitefish (Coregonous sp.). Journla of Evolutionary Biology 22(3): 498-514.

Vos, C.C., Berry, P., Opdam, P., Baveco, H., Nijhof, B., O'Hanley, J., Bell, C., and Kuipers, $H_{\text {., }}$ 2008. Adapting landscapes to climate change: examples of climate-proof ecosystem networks and priority adaptation zones. Journal of Applied Ecology 45(6): $1722-1731$.

Wagner, I, Simons, A.M., 2009. Divergent norms of reaction to temperature in germination characteristics among populations of the arctic-alpine annual, Koenigia isladica. Arctic, Antarctic and Alpine Research 41(3): 388-395.

Walter, G.H., and Patterson, H.E.H., 1994. The implications of palaeontological evidence for theories of ecological communities and species richness. Australian Journal of Ecology 19: 241-250.

Walter, G.R., Post, E., Convey, P., Menzel, A., Parmesan, C., Beebee, T.J.C., Fromentin, J.M., Hoegh-Guidberg, O., and Bairlein, F., 2002. Ecological responses to recent climate change. Nature 416: 389-395.

White, S.L., and Wise, R.R., 1998. Anatomy and Ultrastructure of Wolffia columbiana and Wolffia borealis, two nonvascular aquatic angiosperms. International Journal of Plant Science 159(2): 297-304

Woleck, J., 1974. A preliminary investigation on interactions (competition, allelopathy) between some species of Lemna, Spirodela and Wolffia. Berichte des Geobotanischen Institues der Eidg. Techn. Hochschule, Stiftung Rübel 42:140-162.

Woleck, J., 1984. Interspecific variation and the competitive abilities of Spirodela polyrhiza. (L.). Polish Journal of Ecology 32: 637-649.

Wu, Y., Griffiths, M.W., and McKellar, R.C., A comparison of the bioscreen method and microscopy for the determination of lag times of individual cells of Listeria monocytogenes. Letters in Applied Microbiology 20: 468-472.

Yadugiri, V.T., 2010. Climate change: the role of plant physiology. Current Science 99 : 423-425. 